\title{
Reliability-based design of internal limit states for mechanically stabilized earth walls using geosynthetic reinforcement
}

\begin{tabular}{|r|l|}
\hline Journal: & Canadian Geotechnical Journal \\
\hline Manuscript ID & cgj-2018-0074.R1 \\
\hline Manuscript Type: & Article \\
\hline $\begin{array}{r}\text { Date Submitted by the } \\
\text { Author: }\end{array}$ & 28 -May-2018 \\
\hline $\begin{array}{r}\text { Complete List of Authors: } \\
\text { Keyword: }\end{array}$ & $\begin{array}{l}\text { Bathurst, Richard; Queens University/Royal Military College, } \\
\text { Lin, Peiyuan; Royal Military College of Canada, } \\
\text { Allen, Tony; Washington State Department of Transportation }\end{array}$ \\
\hline $\begin{array}{r}\text { Is the invited manuscript } \\
\text { for consideration in a } \\
\text { Special Issue? : }\end{array}$ & Not applicable (regular submission) \\
\hline
\end{tabular}




\section{Reliability-based design of internal limit states for mechanically stabilized earth walls using geosynthetic reinforcement}

\section{Richard J. Bathurst ${ }^{1}$}

Peiyuan Lin ${ }^{2}$

Tony Allen ${ }^{3}$

\footnotetext{
${ }^{1}$ Professor and Research Director (Corresponding Author)

Department of Civil Engineering GeoEngineering Center at Queen's-RMC

Royal Military College of Canada Kingston, ON, K7K 7B4, Canada

Phone: (613) 541-6000 (ext. 6479/6391); Email: bathurst-r@,rmc.ca

2 Postdoctoral Research Fellow

Department of Civil Engineering

Ryerson Institute of Infrastructure Innovation

Ryerson University, Toronto, Ontario, Canada

Email: peiyuan.lin@ryerson.ca
}

Formerly: Postdoctoral Research Fellow, Department of Civil Engineering, GeoEngineering Center at Queen's-RMC, Royal Military College of Canada

${ }^{3}$ State Geotechnical Engineer

Washington State Department of Transportation

State Materials Laboratory

P.O. Box 47365

Olympia, WA 98504-736

USA

Email: allent@wsdot.wa.gov 


\begin{abstract}
The paper demonstrates reliability-based design for tensile rupture and pullout limit states for mechanically stabilized earth (MSE) walls constructed with geosynthetic (geogrid) reinforcement. The general approach considers the accuracy of the load and resistance models that appear in each limit state equation plus uncertainty due to the confidence (level of understanding) of the designer at time of design. Reliability index is computed using a closedform solution that is easily implemented in a spreadsheet. The general approach provides a quantitative link between nominal factor of safety that is familiar in allowable stress design practice, and reliability index used in modern civil engineering reliability-based design practice. A well-documented MSE wall case study is used to demonstrate the general approach and to compare margins of safety using different load and resistance model combinations. A practical outcome from the case study example is the observation that the pullout limit state is much less likely to control design than the ultimate tensile rupture state for walls with continuous reinforcement coverage. The more accurate Simplified Stiffness Method that is used to compute tensile loads in the reinforcement under operational conditions is shown to generate a more costeffective reinforcement option than the less accurate AASHTO Simplified Method.
\end{abstract}

Author keywords: MSE walls; Geosynthetic reinforcement; Internal stability limit states; Reliability-based design 


\section{Introduction}

The internal stability design of mechanically stabilized earth (MSE) walls in North America, is most often based on load and resistance factor design (LRFD) which is a reliability theory- based approach (AASHTO 2017; FHWA 2009; CSA 2014). The expectation is that when a limit state design equation with load and resistance factors is satisfied, a minimum margin of safety expressed as reliability index (or probability of failure) is assured. However, for any other condition the true margin of safety in probabilistic terms is unknown. Furthermore, the designer may have a choice of load and resistance models to use in a limit state design equation. These models will have different accuracy and thus different combinations of models with the same load and resistance factors will result in different margins of safety in probabilistic terms. An alternative strategy to traditional allowable stress design (ASD) and LRFD for the design and analysis of geotechnical foundations and walls, are true reliability theory-based design (RBD) approaches which offer more flexibility to adjust design parameters in order to meet or exceed a target level of safety (i.e., reliability index or probability of failure) (Low and Phoon 2015; Phoon and Ching 2015; Phoon 2017). In current North American practice, RBD is best promoted as a useful complimentary tool to traditional ASD and LRFD (Low 2017).

The state-of-the-knowledge with respect to reliability-based design of geotechnical foundations from a European (Eurocode) perspective is found in the recent Joint TC205/TC304 Working Group Report (2017). The current study complements this report by providing a North American perspective to reliability-based design as it applies to a particular class of structures with limit states that are well served by simple linear performance functions and for which sufficient performance measurements are available to calibrate the models and quantify model accuracy in probabilistic terms.

This paper builds upon prior related work by the writers and co-workers focused on the collection of load and resistance data from physical measurements of geosynthetic MSE walls under operational conditions, and their components (e.g., Allen et al. 2001; Bathurst et al. 2011; Huang et al. 2009), the development of new load and resistance models (e.g., Allen et al. 2015; Miyata and Bathurst 2012b; Bathurst et al. 2008b), the calibration and statistical 
evaluation of the accuracy of current and proposed new load and resistance models (e.g., Allen and Bathurst 2015, 2018; Huang and Bathurst 2009), lessons learned from closed-form solutions for the calculation of reliability index for simple linear limit state functions and for LRFD calibration (e.g., Allen et al. 2005; Bathurst et al. 2008a; Bathurst et al. 2017; Bathurst and Javankhoshdel 2017), the influence of correlations between variables in model formulations and between nominal load and resistance terms that appear in limit state equations in reliability calculations (e.g., Lin and Bathurst 2018), and the notion of level of understanding that has been recently adopted in Canada for LRFD of foundations (e.g., Fenton et al. 2014). These earlier works provide the background and data that were required to develop for the first time a practical and rigorous reliability-based design approach for tensile rupture and pullout internal limit states for geosynthetic MSE walls.

\section{Objectives and General Approach}

The principal objective of this paper is to demonstrate a new approach for reliability-based design for tensile rupture and pullout internal stability limit states in geosynthetic reinforced soil walls.

In this study only a single load term due to soil self-weight in the reinforcement zone is considered to compute the maximum tensile load in a reinforcement layer under operational conditions. The two limit states considered are tensile rupture and pullout. Two different load models are considered for each limit state. Two different pullout modes are examined for the pullout limit state for geogrid reinforcement products in frictional (i.e., cohesionless) soils. These limit states are shown in Figure 1 using notations and dimensions found in AASHTO (2017) for the case of a MSE wall with continuous reinforcement layers. In this paper, different combinations of load and resistance models are used to demonstrate quantitatively the influence of choice of model on reliability index outcomes. Reliability index $(\beta)$ is computed using a general closed-form solution proposed by Bathurst and Javankhoshdel (2017). Computed outcomes were checked using Monte Carlo simulation and shown to be the same. The advantage of the closed-form solution is that the calculation of $\beta$ (or equivalently probability of failure, $\mathrm{P}_{\mathrm{f}}$ ) can be carried out using a spreadsheet and thus the influence of changes in magnitude of input 
parameters on computed $\beta$ are more readily apparent. The general formulation considers uncertainty in the magnitude of nominal values at time of design, accuracy of the underlying deterministic models that appear in the limit state equations, dependencies between nominal values and method accuracy, and correlations between load and resistance terms.

\section{Load and Resistance Models for Geosynthetic Internal Limit States}

\subsection{Reinforcement Load Models}

The two reinforcement load models considered in this study are the AASHTO/FHWA Simplified Method (AASHTO 2017; FHWA 2009; Allen et al. 2001) and the Simplified Stiffness Method (Allen and Bathurst 2015, 2018). The former is a soil strength-based method that is used routinely for MSE wall internal stability design. The Simplified Stiffness Method is a variant that is based largely on reinforcement stiffness and has been empirically calibrated to improve the agreement between measured and predicted (calculated) reinforcement loads for walls constructed with both relatively inextensible steel reinforcement products and walls with relatively extensible (geosynthetic) reinforcement types. The development and refinement of the current stiffness-based load model for geosynthetic reinforced MSE walls can be traced through a series of earlier papers by Allen et al. (2003), Miyata and Bathurst (2007a,b) and Bathurst et al. (2008b).

In this paper, the AASHTO Simplified Method to calculate the maximum tensile reinforcement load $\left(\mathrm{T}_{\max }\right)$ under operational conditions is called Load Model 1 (LM1) and is expressed as:

$\mathrm{T}_{\max }=\mathrm{S}_{\mathrm{v}} \mathrm{K} \sigma_{\mathrm{v}}=\mathrm{S}_{\mathrm{v}} \mathrm{K}\left(\gamma_{\mathrm{r}} \mathrm{z}+\mathrm{q}\right)$

Here, $S_{v}=$ tributary vertical spacing of the reinforcement layer (Figure 1), $\mathrm{K}=$ horizontal component of the active lateral earth pressure coefficient using the Coulomb earth pressure equation in AASHTO (2017), $\sigma_{v}=$ vertical pressure due to gravity forces from self-weight of the 
reinforced soil wall backfill, $\gamma_{\mathrm{r}}=$ unit weight of the reinforced soil, $\mathrm{q}=$ average vertical pressure due to soil surcharge acting at top of the reinforced soil mass, and $z=$ depth below crest of wall of height $\mathrm{H}$. Coefficient $\mathrm{K}$ is computed as a function of peak friction angle of the reinforced soil backfill $\left(\phi_{\mathrm{r}}\right)$ and wall face batter but ignoring wall-soil interface friction. The peak friction angle is deduced from conventional triaxial compression tests or direct shear box tests as recommended by AASHTO (2017).

Load Model 2 (LM2) in this study is the Simplified Stiffness Method (Allen and Bathurst 2015, 2018). The maximum tensile load in a reinforcement layer $\left(T_{\max }\right)$ under operational conditions is computed as:

$$
\mathrm{T}_{\max }=\mathrm{S}_{\mathrm{v}}\left[\gamma_{\mathrm{r}} \mathrm{HD}_{\text {tmax }}+\left(\mathrm{H}_{\mathrm{ref}} / \mathrm{H}\right) \gamma_{\mathrm{f}} \mathrm{S}\right] \mathrm{K}_{\mathrm{avh}} \Phi_{\mathrm{fb}} \Phi_{\mathrm{g}} \Phi_{\mathrm{fs}} \Phi_{\text {local }} \Phi_{\mathrm{c}}
$$

where, $\mathrm{D}_{\text {tmax }}=$ distribution factor for $\mathrm{T}_{\max }, \mathrm{H}_{\text {ref }}=$ reference wall height $(6 \mathrm{~m}), \mathrm{K}_{\mathrm{avh}}=$ horizontal component of active earth pressure coefficient assuming the wall is vertical, and $\Phi_{\mathrm{fb}}, \Phi_{\mathrm{g}}, \Phi_{\mathrm{fs}}$, $\Phi_{\text {local }}$ and $\Phi_{\mathrm{c}}$ are dimensionless factors that account for the quantitative influence of wall facing batter, global reinforcement stiffness, facing stiffness, local reinforcement stiffness and soil cohesion (respectively) on maximum reinforcement load in a layer. All other parameters have been defined previously. A detailed explanation of Equation 2 and its contents are found in the papers by Allen and Bathurst (2015, 2018) and are not repeated here for brevity. In the analyses to follow only wall cases with cohesionless backfill soils are considered, hence $\Phi_{\mathrm{c}}=1$.

\subsection{Pullout Resistance Models}

The calculation of the ultimate pullout capacity of a geogrid $\left(\mathrm{P}_{\mathrm{c}}\right)$ using the AASHTO/FHWA equation (FHWA 2009; AASHTO 2017) is:

$\mathrm{P}_{\mathrm{c}}=2 \mathrm{~F}^{*} \alpha \sigma_{\mathrm{v}} \mathrm{L}_{\mathrm{e}}$ 
where, $\mathrm{F}^{*}=\frac{2}{3} \tan \phi_{\mathrm{r}}, \alpha=0.8$ and $\mathrm{L}_{\mathrm{e}}=$ reinforcement pullout embedment length (Figure 1).

Equation 3 is called Pullout Model 1 (PM1) in the current study. The second geogrid pullout model considered here is identified as Pullout Model 2 (PM2) and is taken from Huang and Bathurst (2009) and expressed as:

$\mathrm{P}_{\mathrm{c}}=\eta\left(2 \mathrm{~F}^{*} \alpha \sigma_{\mathrm{v}} \mathrm{L}_{\mathrm{e}}\right)^{1+\kappa}$

where, $\eta=5.51$ and $1+\kappa=0.629$. Equations 3 and 4 are used with the default coefficient values shown; thus both are models that are used in the absence of project-specific pullout test data which is the typical case for internal stability design of MSE wall projects. A model of similar form to Equation 4 has been proposed by Miyata and Bathurst (2012b) for geogrid products embedded in cohesive-frictional soils. Their model was calibrated against a database of tests performed in Japan using a Japanese pullout box test protocol.

\subsection{Rupture Resistance Model}

In this investigation the ultimate tensile rupture capacity of the reinforcement is taken as the long-term allowable strength (AASHTO 2017) expressed:

$\mathrm{T}_{\mathrm{al}}=\frac{\mathrm{T}_{\mathrm{ult}}}{\mathrm{RF}}=\frac{\mathrm{T}_{\mathrm{ult}}}{\mathrm{RF}_{\mathrm{ID}} \mathrm{RF}_{\mathrm{CR}} \mathrm{RF}_{\mathrm{D}}}$

The numerator is a reference laboratory ultimate tensile strength $\left(\mathrm{T}_{\mathrm{ult}}\right)$ that is reduced by factors that account for loss of strength over the design life of the reinforcement due to installation damage $\left(R F_{I D}\right)$, creep $\left(R F_{C R}\right)$ and degradation (durability) mechanisms $\left(R_{D}\right)$. Parameter $R F$ is combined reduction factor. 


\section{Closed-form Solution for Calculation of Reliability Index for Simple Limit State Functions}

The general form of the performance functions $(\mathrm{g})$ in this study is:

$g=\lambda_{R} R_{n}-\lambda_{Q} Q_{n}$

where $R_{n}$ and $Q_{n}$ are nominal resistance and nominal load values, and $\lambda_{R}$ and $\lambda_{Q}$ are resistance and load method bias values, respectively. For a pair of data representing the nominal value $\left(\mathrm{R}_{\mathrm{n}}\right.$ or $\left.\mathrm{Q}_{\mathrm{n}}\right)$ and the matching actual measured values $\left(\mathrm{R}_{\mathrm{m}}\right.$ or $\left.\mathrm{Q}_{\mathrm{m}}\right)$ the corresponding bias values are computed as:

$\lambda_{\mathrm{R}}=\mathrm{R}_{\mathrm{m}} / \mathrm{R}_{\mathrm{n}}$

$\lambda_{\mathrm{Q}}=\mathrm{Q}_{\mathrm{m}} / \mathrm{Q}_{\mathrm{n}}$

Stated alternatively, bias values can be understood to be corrections that transform nominal values to true (i.e., measured) values. The expectation is bias values will be lognormally distributed based on prior related work by the writers and others (e.g., ISSMGE 2017). Their magnitude will depend on the accuracy of the underlying deterministic equation for load or resistance (called model bias), plus the uncertainty in model accuracy due to calibration method when model coefficients are determined from back-fitting to measured values (e.g., pullout tests), quantity and quality of data, and consistency in interpretation of data gathered from multiple sources (the typical case). Hence, the same model can have different method bias values depending on how it is calibrated (e.g., calibration of pullout models using pullout box or insitu test results as demonstrated by Miyata and Bathurst (2012b)). The term method bias is notionally similar to the term model factor or model bias which appears elsewhere in the related literature (e.g., ISSMGE 2017). However, because performance function accuracy can vary using the same underlying mechanistic model for the reasons noted above, the writers prefer the more nuanced method bias terminology. In the text to follow, the term bias is used for brevity but is understood to capture more than model error alone as noted above. For a fuller description 
of factors that influence the calculation of method bias, the reader is directed to Allen et al. (2005), Bathurst and Javankhoshdel (2017) and Bathurst et al. (2017).

Assuming all bias and nominal values are lognormally distributed, the reliability index $(\beta)$ for Equation 6 can be computed as:

$$
\beta=\frac{\ln \left[\left(\frac{\mu_{\lambda_{\mathrm{R}}} \mu_{\mathrm{R}_{\mathrm{n}}}}{\mu_{\lambda_{\mathrm{Q}}} \mu_{\mathrm{Q}_{\mathrm{n}}}}\right) \sqrt{\left.\frac{\left(1+\mathrm{COV}_{\mathrm{Qn}}^{2}\right)\left(1+\mathrm{COV}_{\lambda \mathrm{Q}}^{2}\right)}{\left(1+\mathrm{COV}_{\mathrm{Rn}}^{2}\right)\left(1+\mathrm{COV}_{\lambda \mathrm{R}}^{2}\right)}\right]}\right.}{\sqrt{\ln \left[\frac{\left(1+\mathrm{COV}_{\mathrm{Qn}}^{2}\right)\left(1+\mathrm{COV}_{\lambda \mathrm{Q}}^{2}\right)\left(1+\mathrm{COV}_{\mathrm{Rn}}^{2}\right)\left(1+\mathrm{COV}_{\lambda \mathrm{R}}^{2}\right)\left(1+\rho_{\mathrm{R}} \mathrm{COV}_{\mathrm{Rn}} \mathrm{COV}_{\lambda \mathrm{R}}\right)^{2}\left(1+\rho_{\mathrm{Q}} \mathrm{COV}_{\mathrm{Qn}} \mathrm{COV}_{\lambda \mathrm{Q}}\right)^{2}}{\left(1+\rho_{\mathrm{n}} \mathrm{COV}_{\mathrm{Rn}} \mathrm{COV}_{\mathrm{Qn}}\right)^{2}}\right.}}
$$

This equation follows from basic probability theory. All assumptions and full details of its derivation can be found in the appendix to the paper by Bathurst and Javankhoshdel (2017). Parameters $\mu_{\mathrm{Rn}}, \mu_{\mathrm{Qn}}, \mu_{\lambda \mathrm{R}}$ and $\mu_{\lambda \mathrm{Q}}$ are mean values of nominal resistance and load values $\left(\mathrm{R}_{\mathrm{n}}\right.$ and $\left.Q_{n}\right)$, and resistance and load method bias values $\left(\lambda_{R}\right.$ and $\left.\lambda_{Q}\right)$, respectively. The nominal resistance $\left(R_{n}\right)$ value and nominal load value $\left(Q_{n}\right)$ used at design time in the limit state design equations are equivalent to $\mu_{\mathrm{Rn}}$ and $\mu_{\mathrm{Qn}}$ in the above equation. Their corresponding coefficients of variation $(\mathrm{COV})$ are denoted as $\mathrm{COV}_{\mathrm{Rn}}, \mathrm{COV}_{\mathrm{Q}_{\mathrm{n}}}, \mathrm{COV}_{\lambda \mathrm{R}}$ and $\operatorname{COV}_{\lambda Q}$. Parameters $\rho_{\mathrm{R}}$ and $\rho_{\mathrm{Q}}$ are Pearson's correlation coefficients between variables $R_{n}$ and $\lambda_{R}$, and between $Q_{n}$ and $\lambda_{Q}$, respectively, and represent bias dependencies with nominal values. Parameter $\rho_{n}$ is the correlation coefficient between $R_{n}$ and $Q_{n}$ and is called nominal correlation following the terminology introduced by Lin and Bathurst (2018). In the analyses carried out later in this paper, $\rho_{\mathrm{n}}=0$ for the rupture limit state because nominal load values and nominal resistance values are sampled from independent populations. For the pullout limit state the soil material properties and their statistical characteristics are the same for the load equation associated with the active wedge in Figure 1 and the pullout equation associated with the passive zone. Hence, $\rho_{\mathrm{n}} \neq 0$ and will vary with changes in the distributions for friction angle and unit weight assumed at the location of each reinforcement layer as demonstrated by Lin and Bathurst (2018). 
The first term in the numerator of Equation 8 is the operational factor of safety (OFS) (Bathurst et al. 2011) computed as:

$$
\mathrm{OFS}=\left(\frac{\mu_{\lambda \mathrm{R}} \mu_{\mathrm{Rn}}}{\mu_{\lambda \mathrm{Q}} \mu_{\mathrm{Qn}}}\right)=\left(\frac{\mu_{\lambda \mathrm{R}}}{\mu_{\lambda \mathrm{Q}}}\right) \mathrm{F}_{\mathrm{n}}
$$

The operational factor of safety is the true factor of safety for the limit state (performance function) under consideration. Depending on the average values of resistance bias and load bias, OFS can be larger or smaller than the nominal factor of safety $\left(F_{n}\right)$ assumed at time of design. As demonstrated later in this paper for the two limit states considered, OFS is larger than $F_{n}$. This is typical for internal limits states for geosynthetic MSE walls because load models tend to overestimate measured loads (on average) and pullout and tensile strength models tend to underestimate measured resistance (on average) (i.e., $\mu_{\lambda \mathrm{R}} / \mu_{\lambda \mathrm{Q}}>1$ ).

\section{Statistics of random variables}

\subsection{Nominal load and resistance values}

Nominal values for $R_{n}$ and $Q_{n}$ are required as the starting point for limit state analysis and design. For example, best estimates of $\mathrm{T}_{\mathrm{al}}$ and $\mathrm{P}_{\mathrm{c}}$ for rupture and pullout equations correspond to $\mathrm{R}_{\mathrm{n}}$, and $\mathrm{T}_{\max }$ corresponds to $\mathrm{Q}_{\mathrm{n}}$ in limit state equations having the form of Equation 6. As noted earlier, these values are assumed to be mean values of random variables $Q_{n}$ and $R_{n}$ denoted as $\mu_{\mathrm{Rn}}$ and $\mu_{\mathrm{Qn}}$; uncertainty in choice of nominal values (i.e., variability) is captured by $\mathrm{COV}_{\mathrm{Rn}}$ and $\mathrm{COV}_{\mathrm{Qn}}$. In this paper, the magnitudes of these COV values are linked to the notion of level of understanding found in the Canadian Highway Bridge Design Code (CSA 2014) for LRFD of foundations (Fenton et al. 2016). Three levels of understanding are identified as high, typical and low; they are used to select matching resistance factors that increase in the order of low to high level of understanding. The intent is to reward the engineer with a larger resistance factor in a limit state design equation when a higher level of understanding of project conditions can be 
demonstrated. Hence, the choice of level of understanding is admittedly subjective but has the objective to capture the confidence of the designer with the choice of the model used to compute the nominal values for the project conditions, the amount and quality of the project data including material properties and knowledge of ground conditions, familiarity with the wall technology proposed and the applicability of the selected wall technology for the project works. Bathurst and Javankhoshdel (2017) mapped values of COV $=0.10,0.20$ and 0.30 to high, typical and low levels of understanding, respectively. Bathurst et al. (2017) used the same assignments to demonstrate LRFD calibration of simple linear limit state functions having the form of Equation 6 but rewritten with load and resistance factors, and reliability index (Equation 8) expressed with the ratio of bias means in the OFS term replaced with the ratio of load and resistance factor. They also gave an example how the engineer can self-evaluate to select the level of understanding that is appropriate for the case of the pullout limit state in a MSE wall project.

For the rupture limit state, $\mathrm{T}_{\mathrm{al}}$ is taken as the nominal resistance and is computed using Equation 5. The level of understanding for the selection of $\mathrm{T}_{\mathrm{al}}$ at time of design is very high and for this reason COV for nominal resistance (strength) is assumed as zero. The relatively small amount of uncertainty for the true value of $\mathrm{T}_{\mathrm{al}}$ is captured in the bias statistics as discussed later.

\subsection{Load bias statistics and bias dependencies}

In this study the two load models introduced earlier (LM1 and LM2) are used to predict the maximum tensile load in a geogrid reinforcement layer embedded in a frictional (granular) soil. Only granular soils are considered in this study because engineers typically interpret the meaning of "select" fills that are recommended in AASHTO (2017) for the reinforced soil zone in MSE walls, to be cohesionless soils.

Allen and Bathurst (2015) compiled a database of measured maximum tensile loads $\left(\mathrm{T}_{\max }\right)$ from instrumented layers in monitored full-scale MSE walls. A total of $n=96$ values were extracted from this database corresponding to MSE walls constructed with geogrid reinforcement products in combination with granular backfill. Load bias statistics are summarized in Table $\mathbf{1}$ 
and plotted as cumulative distribution function (CDF) plots in Figure 2a. The data trends in these figures are consistent with the assumption that the load bias values are lognormally distributed, particularly at the upper tails. The mean and COV of all bias values for each model are used to compute the fitted approximations shown as solid lines. The AASHTO (2017) Simplified Method can be seen to do poorly when used to predict actual measured $\mathrm{T}_{\max }$ values. Predicted maximum load values are $43 \%$ of measured values (on average) (i.e., mean of bias values is $\mu_{\lambda Q}=0.43$ ) and there is a large spread in model accuracy quantified by the COV of load bias $\mathrm{COV}_{\lambda \mathrm{Q}}=0.95$. In addition, there is a pronounced dependency (correlation) between bias values and predicted $T_{\max }$ values as illustrated in Figure 2b. This means that the accuracy of the load model varies with magnitude of computed (predicted) $T_{\max }$ which is undesirable for both allowable stress design (ASD) and for reliability-based design (RBD). This bias dependency at level of significance of $5 \%$ corresponds to Pearson's correlation coefficient $\rho_{Q}=-0.41$. The accuracy of the second load model (LM2) is much better. The mean and COV of load bias values are 0.96 and 0.36, respectively (Figure 2a) and load bias dependency with predicted loads is very low $\left(\rho_{\mathrm{Q}}=+0.09\right)$ (Figure $\left.2 \mathbf{b}\right)$ and can be taken as zero at a level of significance of $5 \%$. Finally, it can be seen in Figure 2a that the approximations to all data for the bias CDF plots for both models are visually poorer at the lower tails but better at the upper tails. The poorer fit at the lower tails is not a practical concern because it is the upper tails corresponding to large underestimations of load (large load bias values) that reduce reliability index values (i.e., result in higher probabilities of failure) (Allen et al. 2005).

\subsection{Resistance bias statistics and bias dependencies}

As noted earlier, the ultimate pullout limit state using two different pullout capacity models and the ultimate tensile rupture limit state are examined in this paper.

Huang and Bathurst (2009) collected the results of 318 pullout box tests performed on geogrid reinforcement products in combination with cohesionless soils. The geogrid products were integral drawn and punched uniaxial high-density polyethylene (HDPE) and biaxial polypropylene (PP) types, and woven polyester (PET). In the analyses to follow all tests are 
treated as a single population since each group had similar bias statistics using all of the models investigated by Huang and Bathurst (2009).

Bias statistics for the two pullout models are summarized in Table $\mathbf{1}$ and plotted in Figure 3a. Both models give bias distributions that are log-normally distributed. The non-linear model (PM2) can be seen to be a better default model (on average) and has less spread in bias values compared to the current AASHTO (2017) default pullout model (PM1) for geogrid reinforcement layers in cohesionless soils. The approximations to all data in the CDF plots appear reasonable, at least visually, over the entire range of data. Hence, these approximations are judged to provide a satisfactory fit to the lower tails of the bias CDF plots, noting that the lower tails are important contributors to the probability of failure in reliability analysis (i.e., large over-estimations of resistance values contribute to higher probabilities failure) (Allen et al. 2005). Figure 3b shows that there is a strong correlation (dependency) between bias values and predicted pullout capacity using the current AASHTO (2017) pullout model (PM1). As discussed earlier for the load models, this dependency is undesirable because it means that model accuracy varies with predicted pullout capacity. For the non-linear model (PM2) proposed by Huang and Bathurst (2009), the computed correlation between bias and predicted pullout capacity is $\rho_{R}=+0.03$, indicating that there is no correlation between the bias and the pullout capacity at a level of significance of $5 \%$.

Tensile rupture bias statistics values are discussed next. Bathurst et al. (2011, 2012), Miyata et al. (2014) and Miyata and Bathurst (2015) compiled databases of installation damage and creep testing of geosynthetic reinforcement products. Bathurst and Miyata (2015) used these data to develop bias statistics for the combined effect of installation damage and creep on geogrid reinforcement tensile strength at the end of design life. For the three geogrid classification types that appear in the pullout database above, the COV of tensile rupture $\left(\mathrm{T}_{\mathrm{al}}\right)$ bias ranged from 0.04 to 0.14 . A value of $\mathrm{COV}_{\lambda \mathrm{R}}=0.10$ is used in the calculations that appear later in the paper. An additional source of conservativeness in current design practice for the ultimate tensile limit state is that producers report $\mathrm{T}_{\text {ult }}$ values in Equation $\mathbf{5}$ that are lower than the mean of values from quality control testing. This is to ensure that as-delivered products meet minimum project specifications or to position the product with respect to competing products 
from other suppliers. In North American practice the conservative estimation of ultimate tensile strength is most often reported as the minimum average roll value (MARV) which is computed as the average ultimate tensile strength of a roll that is two standard deviations below the average ultimate tensile strength from multiple rolls. In the calculations to follow, this source of conservativeness is captured by assigning the mean of tensile rupture bias $\lambda_{R}=1.10$ (Bathurst et al. 2011) as shown in Table 1.

\section{Sensitivity analysis}

In this section the bias data in Table 1 are used in Equation 8 to explore the influence of choice of nominal factor of safety $\left(F_{n}\right)$ and choice of resistance and load models on operational factor of safety (OFS) and computed reliability index. The nominal factor of safety is the ratio of nominal resistance and nominal load selected by the designer using ASD or the ratio of factored load and factored resistance if the designer is using LRFD. The influence of potential correlation between nominal resistance and load values $\left(\mathrm{R}_{\mathrm{n}}\right.$ and $\left.\mathrm{Q}_{\mathrm{n}}\right)$ on reliability index is also examined.

Figure 4 shows OFS plotted against $F_{n}$. The latter is the factor of safety selected by the designer at time of design for the two limit states considered here. Recall that OFS is the true factor of safety. The data plots show that OFS increases linearly with $F_{n}$, as expected. However, for each limit state the magnitude of OFS for the same nominal factor of safety is larger for combination of models with poorer (average) accuracy (i.e., PM1 and LM1, and TM and LM1) compared to models with better accuracy (i.e., PM2 and LM2, and TM and LM2). For example, if the nominal factor of safety is 1.5 at time of design, the (actual) operational factor of safety for the tensile rupture limit state is 3.84 using the poorer load model (LM1) but is 1.72 using the better load model (LM2).

Figure 5a and 5b show results of reliability analyses using different combinations of load and resistance models for the two limit states examined. For each combination of models, there is a linear increase in reliability index with factor of safety when all other parameters remain the same. However, the location and rate of increase in $\beta$ is influenced by the combination of models and the value of $\mathrm{COV}$ for nominal load and resistance values. To focus on trends, the COV 
values for nominal resistance and load values at time of design are assumed equal and assigned values matching levels of understanding introduced earlier, i.e., $\operatorname{COV}_{\mathrm{Rn}}=\mathrm{COV}_{\mathrm{Qn}}=0.1,0.2$ and 0.3. For the same combination of models and the same factor of safety, the reliability index increases with increasing level of understanding. Superimposed on the figures is the reliability index interval from $\beta=2.33$ to 3.09. These limits correspond to probabilities of failure from $\mathrm{P}_{\mathrm{f}}=$ $1 / 100$ to $1 / 1000$. The lower value is the minimum value recommended for load and resistance factor design (LRFD) calibration for soil-structures with multiple elements that provide strength redundancy (Allen et al. 2005). For the case of MSE walls, if one reinforcement layer fails due to pullout or tensile rupture the other layers can compensate.

Figure 5a shows that the combination of poor pullout model (PM1) and poor load model (LM1) give higher values of reliability index than the combination of better pullout model (PM2) and better load model (LM2). This may appear to be counter-intuitive but can be understood to be the result of the additional margin of safety afforded by the combination of a load model that over-estimates actual loads by a large margin and a resistance model that under-estimates actual pullout capacity by a large margin (on average).

The plots in Figure 5a show that for typical level of understanding $\left(\operatorname{COV}_{\mathrm{Rn}}=\mathrm{COV}_{\mathrm{Qn}}=0.2\right)$ and the combination of poor load and resistance models, the range of factor of safety to give $\beta$ values that fall within the interval shown in the plot is $F_{n}=1.15$ to 2.22 . For the same level of understanding and the combination of better load and resistance models the range of factor of safety must be $F_{n}=3.50$ to 5.40 for computed $\beta$ to fall within the same range. Similar qualitative trends appear in Figure 5b for the tensile rupture limit state and typical level of understanding. However, in this figure the range of factors of safety for $\beta$ to fall within the $\beta$ target interval are closer for the case of poor and better load models. This is because the same resistance model (TM) is used for both cases and uncertainty in computed resistance values (tensile strength) using this model is small.

The plots in Figure 5a show that the magnitude of reliability index for the same factor of safety increases with increasing level of understanding for the combination of better load and resistance 
models (PM2 and LM2). However, the reverse is true when the combination with poorer load and resistance models is used (PM1 and LM1). This result may appear counter-intuitive but it is a consequence of the combination of mean bias values, higher COV of bias values and the larger negative values for bias dependency for the PM1 and LM1 models when these values are used in Equation 8.

Equation 8 includes the correlation coefficient $\rho_{n}$ between nominal resistance and load values $\left(R_{n}\right.$ and $\left.Q_{n}\right)$. In the calculations thus far this value has been taken as $\rho_{n}=0$. However, Lin and Bathurst (2018) demonstrated soil-structure limit states scenarios where this value is not zero. For these cases, ignoring correlation between nominal load and resistance terms in a limit state equation (performance function) can over-estimate or under-estimate the computed reliability index depending on the sign and magnitude of $\rho_{\mathrm{n}}$. The influence of magnitude $\rho_{\mathrm{n}}$ on computed $\beta$ using the bias statistics in Table 1 for the pullout limit state is shown in Figure 6. The plots show that for the nominal factors of safety $\left(F_{n}\right)$ used in each set of calculations, the computed $\beta$ value can fall above or below the target $\beta$ interval introduced earlier.

Taken together the plots in Figures 5 and $\mathbf{6}$ demonstrate that design outcomes that fall within an accepted reliability index range may not correspond to factors of safety that are acceptable by the design engineer based on past practice within an allowable stress design framework.

\section{Example reliability-based design of internal limit states}

\subsection{General}

Allen and Bathurst (2014a,b) described the design and analysis of a pair of production walls constructed in the state of Washington in the United States. A cross-section view of one wall designated GW26D is presented in Figure 7. The internal stability design against tensile rupture was carried out using an earlier version of the Simplified Stiffness Method called the K-stiffness Method (Bathurst et al. 2008b). The Simplified Stiffness Method extended the K-stiffness method to taller walls and introduced some changes to improve the utility of the general 
approach and give a modest increase in load prediction accuracy. The practical differences in analysis outcomes between the two methods are minor for this wall example. The same wall was used by Allen and Bathurst (2018) to demonstrate calculation details using the current Simplified Stiffness Method and to compare predicted $\mathrm{T}_{\max }$ values with values using the current AASHTO (2017) Simplified Method. Key properties and dimensions of this wall are given in Table 2. The additional input parameters required for the Simplified Stiffness Method are presented in Table 3.

Wall GW26D was included in the database of monitored walls used to calibrate the Simplified Stiffness Method (Allen and Bathurst 2015) and earlier variants, and to compute the load bias statistics and bias dependencies summarized in Table 1. The select granular soil used for wall GW26D falls within the envelope of pullout box tests used to generate the pullout bias statistics in the same table. Finally, the uniaxial HDPE geogrid in this case study is a typical product for this type of geogrid and appears in the database of tensile rupture tests used to generate the bias statistics for limit state (TM) in Table 1. Hence, the bias statistics and bias dependencies in Table 1 are appropriate for internal stability reliability analyses of this wall.

\subsection{Pullout limit state}

For the pullout limit state analyses to follow, the nominal reinforcement embedment length $\left(\mathrm{L}_{\mathrm{e}}\right)$ is computed assuming: a) $\mathrm{L} / \mathrm{H}=0.7$, which is the recommended minimum ratio in AASHTO (2017) for typical walls, hence $L_{e}$ varies with depth $z$, and; b) $L_{e}=0.9 \mathrm{~m}$, which is the minimum recommended embedment length in the same document. Figure 7 shows that the actual reinforcement lengths are much longer than required to satisfy $\mathrm{L} / \mathrm{H}=0.7$ (i.e., $\mathrm{L} \sim 8 \mathrm{~m}$ ). This greater length was required to satisfy external stability for the reinforced soil mass for this particular wall.

Table 4 summarizes computed margins of safety adopting each criterion above with the current AASHTO (2017) pullout model (PM1) and load model (LM1). Numerical outcomes assuming no correlation between nominal load and resistance terms are discussed first (i.e., $\rho_{\mathrm{n}}=0$ ) (e.g., columns 11 and 21). Pullout model (PM1) and load model (LM1) have been shown earlier to be 
conservative for design because they under-estimate pullout capacity and over-estimate reinforcement loads when compared to measured values. Not surprising, the data in Table 4 show that nominal factors of safety against pullout are very high (columns 7 and 17). Even with the least restrictive length criterion $\left(\mathrm{L}_{\mathrm{e}}=0.9 \mathrm{~m}\right)$, the minimum nominal factor of safety is $\mathrm{F}_{\mathrm{n}}=$ 3.2 (column 17) which is much greater than (say) 1.5 which is a typical recommended minimum factor of safety for ASD (e.g., CFEM 2006). This value can also be linked to the ratio of load and resistance factor $\left(\gamma_{\mathrm{Q}}, \varphi\right)$ used for the pullout and rupture limit states for MSE walls in LRFD practice (i.e., $\left.F_{n}=\gamma_{Q} / \varphi=1.35 / 0.90=1.5\right)($ AASHTO 2017). The true factor of safety computed as OFS is about 5 times larger than the nominal factor of safety $F_{n}$ (columns 8 and 18). The corresponding margin of safety in terms of reliability index is $\beta=3.52$, assuming typical level of understanding (column 21). This value is equivalent to a probability of failure of about $\mathrm{P}_{\mathrm{f}}=$ $0.02 \% \sim 1 / 4600$ which is much lower than 1/100 which has been recommended for strengthredundant MSE wall internal limit states design as discussed earlier. Regardless of the magnitude of margins of safety, the minimum margin of safety corresponds to the top layer; this is the typical expectation for experienced MSE wall designers when reinforcement lengths are the same for all layers.

Figure 8a shows computed $R_{n}$ and $Q_{n}$ data pairs using Monte Carlo simulation and assuming that $\phi_{\mathrm{r}}$ and $\gamma_{\mathrm{r}}$ that appear in Equations 1 and $\mathbf{3}$ are sampled from the same two populations. This is a reasonable assumption since the soil in the reinforced soil zone is the same material in both the active and passive (anchorage) zones (Figure 1). A total of $10^{6}$ Monte Carlo simulations were carried out with $\mathrm{COV}$ of friction angle and soil unit weight taken as $\operatorname{COV}_{\phi}=0.10$ and $\mathrm{COV}_{\gamma}=0.05$, respectively. Both distributions were assumed to be lognormally distributed with mean of friction angle $\mu_{\phi}=38^{\circ}$ and the mean of unit weight $\mu_{\gamma}=20.4 \mathrm{kN} / \mathrm{m}^{3}$ matching the (deterministic) design values reported by Allen and Bathurst (2018). The low spread in soil properties is consistent with an engineered cohesionless fill placed and compacted to meet a typical compaction specification. Potential correlation between $\phi_{\mathrm{r}}$ and $\gamma_{\mathrm{r}}$ in these calculations was ignored because the COV of these parameters are small. Only 3000 data points are shown in Figure 8a for visual clarity. For the calculations thus far, the anchorage length $\left(\mathrm{L}_{\mathrm{e}}\right)$ was treated as deterministic using the values shown in Table 4 (columns 5 and 15). This assumption gave the same correlation coefficient value of $\rho_{n}=-0.79$ for all layers. 
An interesting observation from Figure 8a and $\mathbf{8 b}$ discussed next is that the COV for the computed nominal and resistance values based on $10^{6}$ Monte Carlo simulations was in the range of 0.1 to 0.2 . These values cannot be directly connected to the values of $\mathrm{COV}_{\mathrm{Qn}}$ and $\mathrm{COV}_{\mathrm{Rn}}=$ 0.1, 0.2 and 0.3 that have been used to quantify levels of understanding. This is because the latter are subjective and reflect other sources of uncertainty, not just the expected variability in soil parameters. However, it is encouraging that the COV of the data in Figures $\mathbf{8 a}$ and $\mathbf{8 b}$ are in the same range as $\mathrm{COV}_{\mathrm{Qn}}$ and $\mathrm{COV}_{\mathrm{Rn}}$.

Lin and Bathurst (2018) demonstrated that the magnitude of $\rho_{\mathrm{n}}$ was sensitive to the ratio of $\mathrm{COV}_{\phi} / \mathrm{COV}_{\gamma}$; hence, the same calculations were repeated with the COVs for friction angle and unit weight reversed (i.e., $\mathrm{COV}_{\phi}=0.05$ and $\mathrm{COV}_{\gamma}=0.10$ ) (Figure 8b). In this case the correlation coefficient value was $\rho_{\mathrm{n}}=+0.26$ for all layers. Clearly, the choice of COV for $\phi_{\mathrm{r}}$ and $\gamma_{\mathrm{r}}$ can have a large influence on magnitude and sign of the correlation coefficient between nominal load and resistance. The minimum possible value for correlation coefficient is $\rho_{\mathrm{n}}=-1.0$. The influence of choice of $\rho_{\mathrm{n}}=+0.26,0,-0.79$ and -1.0 on $\beta$ for the case of typical understanding and $\mathrm{L}_{\mathrm{e}}=0.9 \mathrm{~m}$ is shown in Table 4 (columns 20, 21, 22 and 23). The reliability index $\beta$ decreases in magnitude with decreasing (more negative) $\rho_{\mathrm{n}}$. This trend is expected from the last parenthetical term in the denominator of Equation 8. For correlation $\rho_{\mathrm{n}}=-1.0$ and typical level of understanding, $\beta=3.33$ which is well above a minimum target value of $\beta=2.33$.

Calculations for $\beta$ were repeated using Monte Carlo simulation with $\mathrm{L}_{\mathrm{e}}$ computed for each realization using the sampled value of $\phi_{r}$. Hence, for each realization the value of $L_{e}$ changes. These calculations gave some $\beta$ values that were lower than those shown in Table 4 but are not shown for brevity. The lowest calculated value was $\beta=3.21$ corresponding to the top layer of reinforcement, nominal value of $\mathrm{L}_{\mathrm{e}}=0.9 \mathrm{~m}$ and low level of understanding. Again, this value is well above a minimum target value of $\beta=2.33$; hence, all computed $\beta$ values thus far in this example using rigorous Monte Carlo simulation or the closed-form solution are on the safe side for design for all layers and all levels of understanding. 
The calculations above were repeated using the better load model (LM2) and the better pullout model (PM2) and the closed-form solution for $\beta$. The results are summarized in Table 5. Qualitative trends noted above are also true for these data but margins of safety expressed as nominal factor of safety, OFS and reliability index are all greater. The improved accuracy of the load and resistance models (on average) is the reason that the true factors of safety (OFS) are closer to the nominal factor of safety values. Nevertheless, the margins of safety in terms of nominal factor of safety and reliability index are excessively high and well beyond minimums of $\mathrm{F}_{\mathrm{n}}=1.5$ and $\beta=2.33$ recommended earlier.

The discussion and results in this section show that the choice of nominal correlation value is not of practical concern in this example. A value of $\rho_{n}=-1.0$ is a convenient and safe estimate for design, and calculations for $\beta$ are simplified if $L_{e}$ is taken as deterministic for each layer.

The practical implications of the numerical outcomes shown in Tables $\mathbf{4}$ and $\mathbf{5}$ is that pullout is not a concern for this wall regardless if the margins of safety are expressed in ASD or RBD frameworks. This conclusion is consistent with the expectation of experienced designers that pullout failure of typical well-designed geosynthetic reinforced MSE walls with continuous reinforcement coverage and granular fills will not occur if the conditions assumed at design time remain unchanged. Indeed, for these conditions, such failures are undocumented in the literature to the best knowledge of the writers.

\subsection{Tensile rupture limit state}

Margins of safety for the tensile rupture limit state are summarized in Table 6 using the current AASHTO (2017) tensile strength (resistance) method (TM) to compute the resistance term together with the two load models introduced earlier (LM1 and LM2). The resistance term is $\mathrm{Q}_{\mathrm{n}}$ $=\mathrm{T}_{\mathrm{al}}=15.1 \mathrm{kN} / \mathrm{m}$ representing the geogrid reinforcement used in this project and is calculated using Equation 5 with combined reduction factor RF = 3.6 (Allen and Bathurst 2018).

Since nominal load and resistance terms are uncorrelated, $\rho_{n}=0$ in all calculations. The results of calculations show that the nominal factor of safety $F_{n} \geq 1$ is satisfied (or almost satisfied for 
Layer 2) using current AASHTO (2017) load and resistance models (LM1 and TM). Due to conservativeness in both models the (actual) operational factor of safety (OFS) for this limit state is 2.6 times higher, and hence the lowest value for OFS = 2.3 (Layer 2). However, a minimum target reliability $\beta=2.33$ is not satisfied for reinforcement layers over the bottom half of the wall regardless of the level of understanding used in the calculations.

An interesting observation for these results is that $\beta$ values increase slightly in order of high to low level of understanding for each reinforcement layer. The reason for this trend has been explained earlier in the discussion of Figure 5a. The difference in $\beta$ values for the three levels of understanding are not of practical concern in this example since almost all values are less than 2.33 .

For the same calculations using the less conservative Simplified Stiffness Method (LM2) to compute loads in the reinforcement layers with the same geogrid, the nominal factor of safety is $\mathrm{F}_{\mathrm{n}} \geq 4.0$ and $\beta \geq 3.31$ for all layers and all levels of understanding using the project reinforcement. Hence, the current design for the ultimate tensile limit state is more than adequate for all layers using ASD and RBD approaches in combination with the more accurate load model (LM2).

A strategy to reduce the margins of safety in Table 6 to minimum acceptable values using the Simplified Stiffness Method load model (LM2) is to employ a similar uniaxial HDPE geogrid with lower strength and stiffness. Allen and Bathurst (2018) collected stiffness (J) and ultimate load $\left(\mathrm{T}_{\mathrm{ult}}\right)$ data from NTPEP (2017) reports for the same product line as the geogrid used in wall GW26D. They extrapolated these data to identify a similar but hypothetical product with $\mathrm{T}_{\text {ult }}=$ $24 \mathrm{kN} / \mathrm{m}$ and $\mathrm{J}=128 \mathrm{kN} / \mathrm{m}$. Assuming that the combined reduction factor of $\mathrm{RF}=3.6$ used for the as-built wall is applicable to this weaker geogrid, then $T_{a l}=6.7 \mathrm{kN} / \mathrm{m}$.

Numerical outcomes are summarized in Table 7. As expected, nominal factors of safety and reliability index values are lower using current load and resistance models for the tensile rupture limit state. When the more accurate load model is used in the calculations, both nominal factor of safety values and $\beta$ values are lower than for the case with the stronger geogrid, but all values are 
acceptable. For example, the minimum nominal factor of safety is $F_{n}=2.7>1$ and the minimum $\beta=2.55>2.33$. However, margins of safety are unacceptably low using both ASD and RBD approaches as shown in Table 7 for the combination of the current AASHTO (2017) resistance model (TM) and the current (less accurate) AASHTO (2017) Simplified Method (load model LM1).

The data in Table 7 are plotted in Figure 9 to visually summarize the design outcomes described above.

\section{Conclusions}

A general approach for reliability analysis and design for pullout and tensile rupture limit states for geosynthetic-reinforced MSE walls with simple geometry and continuous reinforcement layers (sheets) is proposed. In AASHTO (2017) terminology the reinforcement coverage ratio in this paper is $\mathrm{R}_{\mathrm{c}}=1$.

The general approach considers the accuracy of the load and resistance models that appear in each limit state equation (performance function) plus uncertainty due to the confidence (level of understanding) of the designer at time of design. The notion of level of understanding and its effect on choice of resistance factors is consistent with current LRFD practice in Canada (CSA 2014; Fenton et al. 2016).

The general approach provides a quantitative link between nominal factor of safety that is familiar in ASD practice and reliability index that is the margin of safety used in modern civil engineering RBD practice. Parametric analyses presented in this paper demonstrate how default load and resistance models of different accuracy can influence the magnitude of conventional nominal factor of safety, operational (true) factor of safety and reliability index ( $\beta$ ) (or equivalently probability of failure).

The approach is implemented using a closed-form solution by Bathurst and Javankhoshdel (2017) based on rigorous probability theory and easily implemented in a spreadsheet. While the 
same numerical results using this equation can be calculated using Monte Carlo simulation, the closed-form solution offers the designer transparency with respect to the influence of uncertainty in nominal values selected at time of design and method bias on the calculation of reliability index. The experience of the authors is that many, if not most MSE wall designers are unfamiliar with MC simulation techniques, or at best view the method as tedious, but are comfortable putting an equation into a spreadsheet. The utility of the closed-form solution to compute reliability index is a valuable incentive to encourage practicing engineers to move away from ASD and LRFD, and evaluate design solutions in probabilistic terms.

A well-documented constructed MSE wall case study reported by Allen and Bathurst (2018, 2014b) is used to demonstrate the general approach and to compare margins of safety using two different pullout and load model combinations. The Simplified Stiffness Method (Allen and Bathurst 2015) load model allows a more cost-effective MSE wall solution by using a weaker and less stiff geogrid than the geogrid that was used in original design. This cheaper design outcome is not possible using the current AASHTO (2017) Simplified Method load model because margins of safety computed using ASD and RBD approaches are unacceptably low.

Another practical outcome from this study and the case study example is the observation that the pullout limit state is much less likely to control design than the ultimate tensile rupture state. In fact, because of the prescriptive excessive reinforcement lengths used for external stability calculations (notably base sliding) the margins of safety for the pullout limit state in both ASD and RBD are well above minimum acceptable values regardless of which pullout model is used. Hence, the choice of which pullout model to use for design of MSE walls with continuous (sheet) reinforcement layers may not be a practical concern for most walls. However, this outcome may not be true for MSE walls constructed with other reinforcement types and lower reinforcement coverage ratios.

\section{Acknowledgements}


The authors are grateful for financial support through an ENGAGE research grant awarded to the first author by the Natural Sciences and Engineering Research Council of Canada (NSERC) (Grant Number: 94344-2013) and the Ministry of Transportation of Ontario (MTO) Highway Infrastructure Innovations Funding Program (Grant Number: 9017-R-0030).

\section{ABBREVIATIONS}

$\begin{array}{ll}\text { AASHTO } & \text { American Association of State Highway and Transportation Officials } \\ \text { ASD } & \text { allowable stress design } \\ \text { CDF } & \text { cumulative distribution function } \\ \text { CFEM } & \text { Canadian Foundation Engineering Manual } \\ \text { CSA } & \text { Canadian Standards Association } \\ \text { HDPE } & \text { high-density polyethylene } \\ \text { ISSMGE } & \text { International Society for Soil Mechanics and Geotechnical Engineering } \\ \text { LRFD } & \text { load and resistance factor design } \\ \text { MARV } & \text { minimum average roll value } \\ \text { MC } & \text { Monte Carlo (simulation) } \\ \text { MSE } & \text { mechanically stabilized earth } \\ \text { PP } & \text { polypropylene } \\ \text { PET } & \text { polyester } \\ \text { RBD } & \text { reliability-based design }\end{array}$

\section{References}

Allen, T.M., and Bathurst, R.J. 2014a. Performance of an $11 \mathrm{~m}$ high block-faced geogrid wall designed using the K-stiffness Method. Canadian Geotechnical Journal 51(1): 16-29.

Allen, T.M., and Bathurst, R.J. 2014b. Design and performance of a $6.3 \mathrm{~m}$ high block-faced geogrid wall designed using the K-stiffness Method. ASCE Journal of Geotechnical and 
Geoenvironmental Engineering 142(2): 04013016.

Allen, T.M., and Bathurst, R.J. 2015. An improved simplified method for prediction of loads in reinforced soil walls. ASCE Journal of Geotechnical and Geoenvironmental Engineering 141(11): 04015049.

Allen, T.M., and Bathurst, R.J. 2018. Application of the Simplified Stiffness Method to design of reinforced soil walls. ASCE Journal of Geotechnical and Geoenvironmental Engineering 144(5): 04018024.

Allen, T.M., Bathurst, R.J., Walters, D.L., Holtz, R.D. and Lee, W.F. 2003. A new working stress method for prediction of reinforcement loads in geosynthetic walls. Canadian Geotechnical Journal 40(5): 976-994.

Allen, T.M., Christopher, B.R., Elias, V., and DiMaggio, J.D. 2001. Development of the Simplified Method for Internal Stability Design of Mechanically Stabilized Earth (MSE) Walls, Washington State Department of Transportation (WSDOT) Research Report WA-RD $513.1,96 \mathrm{p}$.

Allen, T.M., Nowak, A.S., and Bathurst, R.J. 2005. Calibration to Determine Load and Resistance Factors for Geotechnical and Structural Design, Transportation Research Board Circular E-C079, Washington, DC, 93 p.

AASHTO. 2017. LRFD Bridge Design Specifications, 8th Ed., American Association of State Highway and Transportation Officials (AASHTO), Washington DC.

Bathurst, R.J., Huang, B., and Allen, T.M. 2011. Analysis of installation damage tests for LRFD calibration of reinforced soil structures. Geotextiles and Geomembranes 29(3): 323-334.

Bathurst, R.J., Huang, B., and Allen, T.M. 2012. Interpretation of laboratory creep testing for reliability-based analysis and load and resistance factor design (LRFD) calibration. Geosynthetics International 19(1): 39-53.

Bathurst, R.J., Javankhoshdel, S., and Allen, T.M. 2017. LRFD calibration of simple soilstructure limit states considering method bias and design parameter variability. ASCE Journal of Geotechnical and Geoenvironmental Engineering 143(9): 04017053-1-14.

Bathurst, R.J., and Javankhoshdel, S. 2017. Influence of model type, bias and input parameter 
variability on reliability analysis for simple limit states in soil-structure interaction problems. Georisk 11(1): 42-54.

Bathurst, R.J., and Miyata, Y. 2015. Reliability-based analysis of combined installation damage and creep for the tensile rupture limit state of geogrid reinforcement in Japan. Soils and Foundations 55(2): 437-446.

Bathurst, R.J., Allen, T.M., and Nowak, A.S. 2008a. Calibration concepts for load and resistance factor design (LRFD) of reinforced soil walls. Canadian Geotechnical Journal, 45(10): 13771392.

Bathurst, R.J., Miyata, Y., Nernheim, A., and Allen, T.M. 2008b. Refinement of K-stiffness method for geosynthetic reinforced soil walls. Geosynthetics International 15(4): 269-295.

Canadian Foundation Engineering Manual (CFEM) 2006. 4 $4^{\text {th }}$ Edition, Canadian Geotechnical Society, Richmond BC, Canada, 488 p.

Canadian Standards Association (CSA) 2014. Canadian Highway Bridge Design Code. CAN/CSA-S6-14, Mississauga, Ontario, Canada.

Fenton, G.A., Naghibi, F., Dundas, D., Bathurst, R.J., and Griffiths, D.V. 2016. Reliability-based geotechnical design in the 2014 Canadian Highway Bridge Design Code. Canadian Geotechnical Journal 53(5): 236-251.

Huang, B. and Bathurst, R.J. 2009. Evaluation of soil-geogrid pullout models using a statistical approach. ASTM Geotechnical Testing Journal 32(6): 489-504.

ISSMGE 2017. Joint TC205/Tc304 Working Group on "Discussion of Statistical/Reliability Methods for Eurocodes" Final Report. International Society for Soil Mechanics and Geotechnical Engineering (ISSMGE). London, UK. 209 p.

Lin, P., and Bathurst, R.J. 2018. Influence of cross-correlation between nominal load and resistance on reliability-based design for simple linear soil-structure limit states. Canadian Geotechnical Journal 55(2): 279-295.

Low, B.K. 2017. Insights from reliability-based design to complement load and resistance factor design approach. Journal of Geotechnical and Geoenvironmental Engineering, 143(11): 04017089. 
Low, B.K., and Phoon, K.K. 2015. Reliability-based design and its complementary role to Eurocode 7 design approach. Computers and Geotechnics 65: 30-44.

Miyata, Y., and Bathurst, R.J. 2012a. Analysis and calibration of default steel strip pullout models used in Japan. Soils and Foundations 52(3): 481-497.

Miyata, Y., and Bathurst, R.J. 2012b. Reliability analysis of soil-geogrid pullout models in Japan. Soils and Foundations 52(4): 620-633.

Miyata, Y., and Bathurst, R.J. 2015. Reliability analysis of geogrid installation damage test data in Japan. Soils and Foundations 55(2): 393-403.

Miyata, Y., Bathurst, R.J., and Allen, T.M. 2014. Reliability analysis of geogrid creep data in Japan. Soils and Foundations 54(4): 608-620.

NTPEP 2007. Use and Application of NTPEP Geosynthetic Reinforcement Test Results, 1135 National Transportation Product Evaluation Program, American Association of State Highway and Transportation Officials (AASHTO), Washington, D.C., USA.

Phoon, K.K. 2017. Role of reliability calculations in geotechnical design. Georisk: Assessment and Management of Risk for Engineered Systems and Geohazards 11(1): 4-21.

Phoon, K.K., and Ching, J. 2015. Is there anything better than LRFD for simplified geotechnical RBD? (pp. 3-15). IOS Press. 
Figure Captions

Figure 1. Problem geometry and internal pullout and rupture limit states for geogrid MSE wall using AASHTO (2017).

Figure 2. Load bias data: (a) CDF plots of load bias, and (b) load bias versus predicted $\mathrm{T}_{\max }$ values

Figure 3. Resistance (pullout) bias data: (a) CDF plots of pullout bias, and (b) pullout bias versus predicted $\mathrm{P}_{\mathrm{c}}$ values

Figure 4. Operational factor of safety $\left(\mathrm{OFS}=\left(\frac{\mu_{\lambda \mathrm{R}}}{\mu_{\lambda Q}}\right) F_{n}\right)$ versus factor of safety $\left(F_{n}=\frac{\mu_{\lambda R}}{\mu_{\lambda Q}}=\frac{R_{n}}{Q_{n}}\right)$ for pullout and tensile rupture limit states using different models

Figure 5. Reliability index $(\beta)$ versus factor of safety $\left(F_{n}\right)$ for different load and resistance models and levels of understanding: (a) pullout limit state; and (b) tensile rupture limit state

Figure 6. Reliability index $(\beta)$ versus nominal correlation coefficient $\left(\rho_{n}\right)$ for different load and resistance (pullout) models and levels of understanding

Figure 7. Wall GW26D used in design example (dimensions from Allen and Bathurst 2014b, 2018)

Figure 8. $\mathrm{R}_{\mathrm{n}}$ versus $\mathrm{Q}_{\mathrm{n}}$ for layer 5 using load model (LM1) and resistance model (PM1) with $\mu_{\phi}=$ $38^{\circ}$ and $\mu_{\gamma}=20.4 \mathrm{kN} / \mathrm{m}^{3}$ : (a) $\operatorname{COV}_{\phi}=0.10, \operatorname{COV}_{\gamma}=0.05$ and; (b) $\operatorname{COV}_{\phi}=0.05, \mathrm{COV}_{\gamma}=0.10$. Note: Only $n=3000$ data points shown for clarity; calculations for Layer 5 with $\mathrm{L}_{\mathrm{e}}=3.14$

Figure 9. Reliability index for reinforcement layers in Wall GW26D using geogrid with $\mathrm{T}_{\text {ult }}=24$ $\mathrm{kN} / \mathrm{m}$ and $\mathrm{J}=128 \mathrm{kN} / \mathrm{m}$ in design example (data from Table 7) 


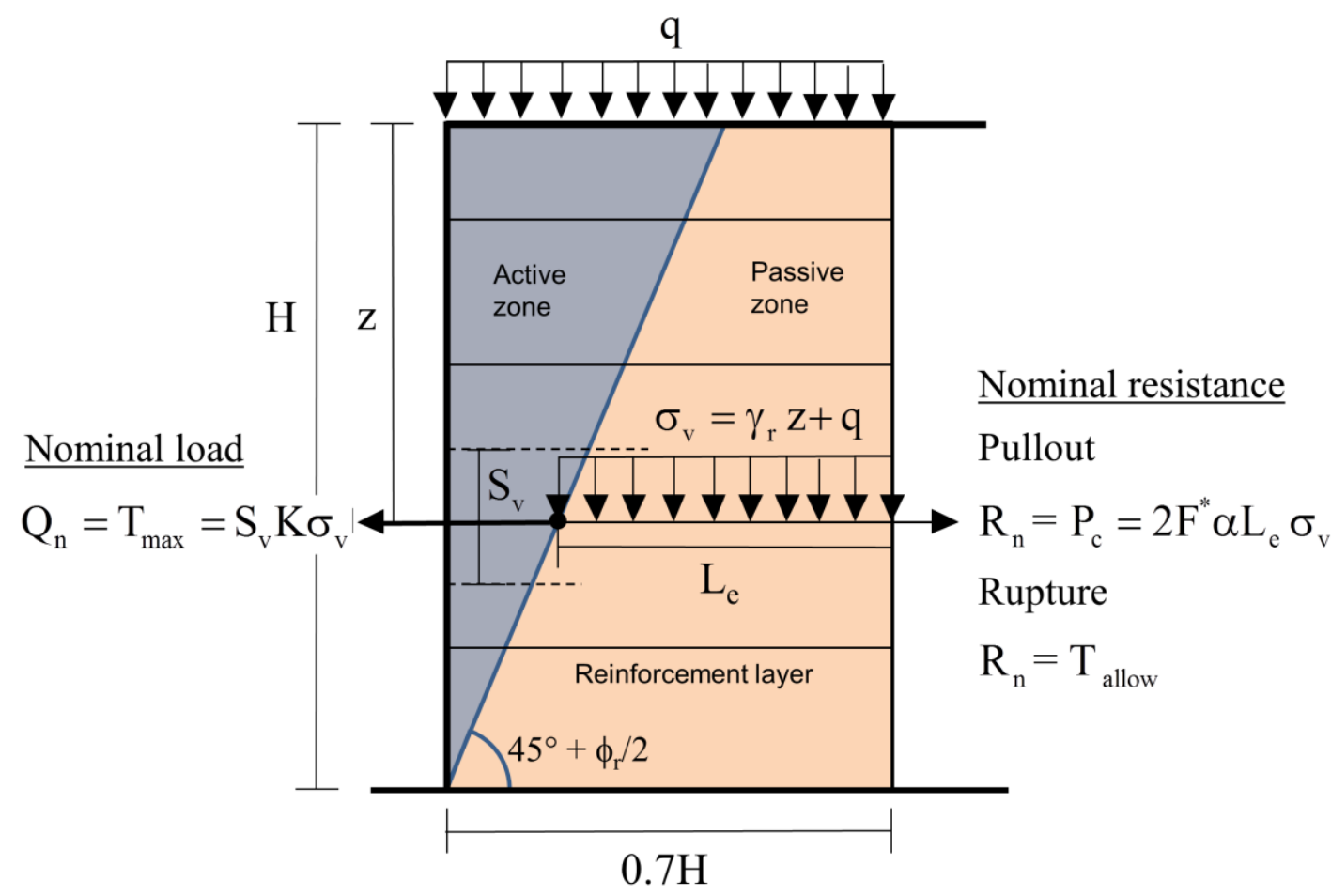

Figure 1. Problem geometry and internal pullout and rupture limit states for geogrid MSE wall using AASHTO (2017) 


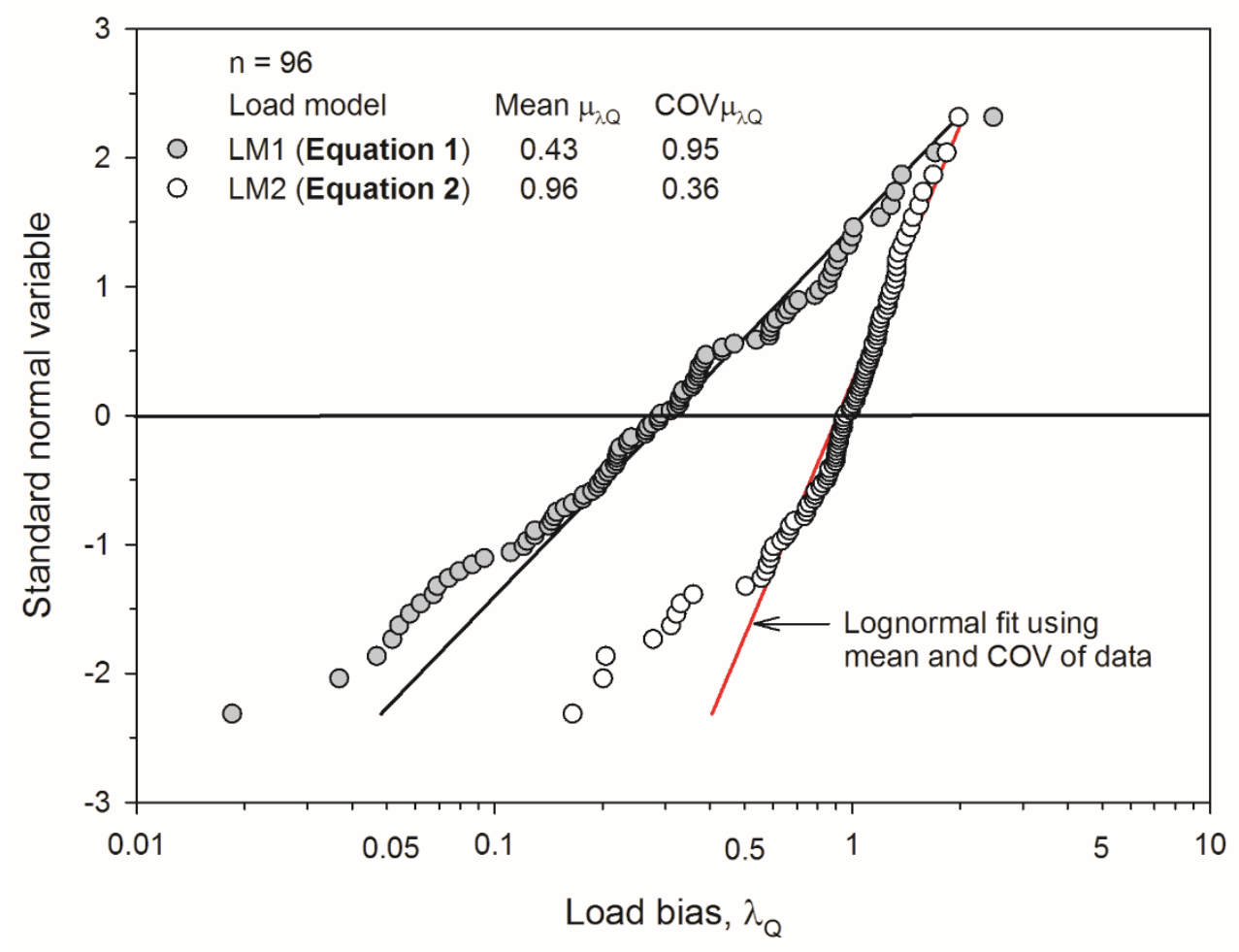

(a)

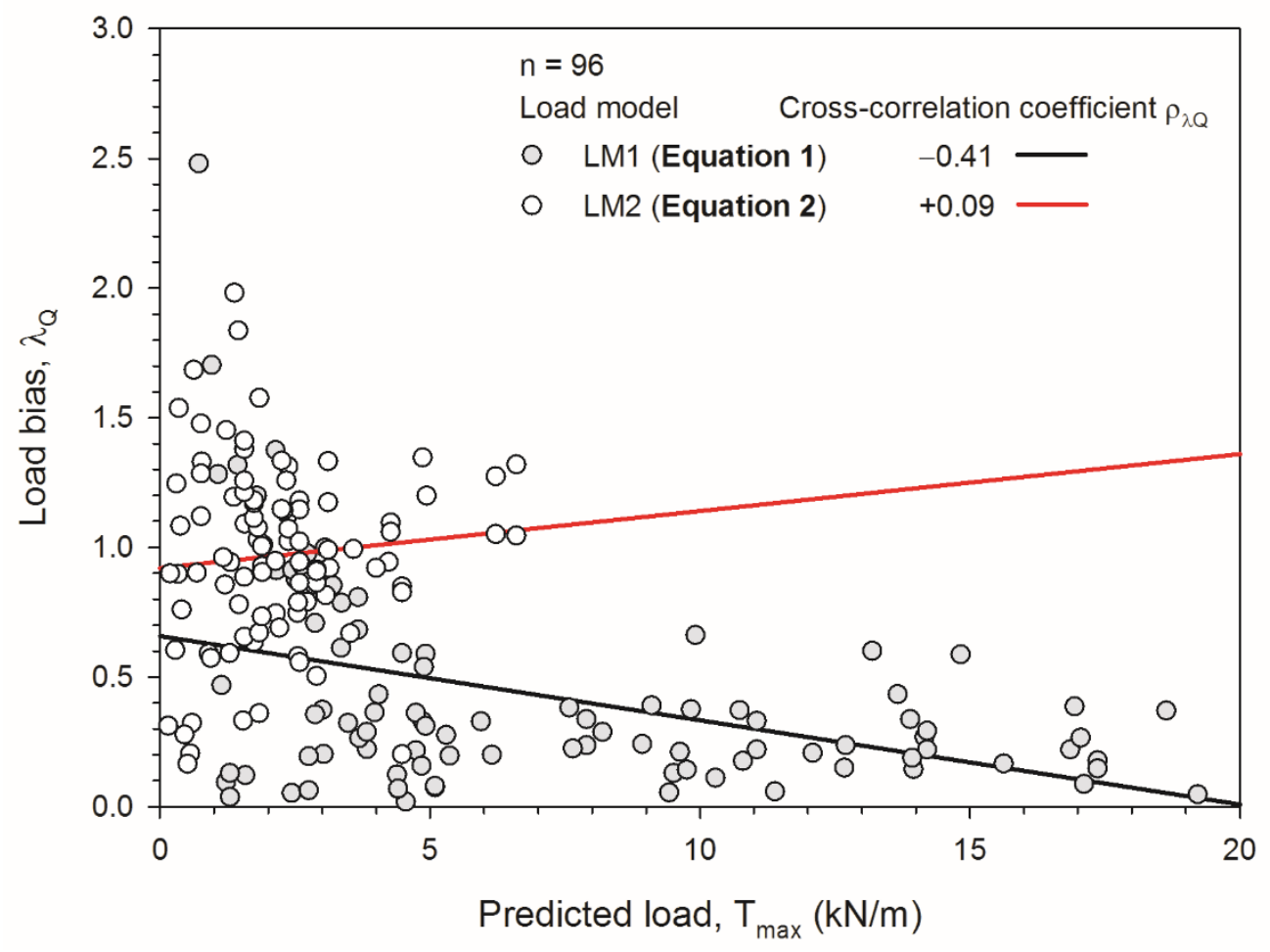

(b)

Figure 2. Load bias data: (a) CDF plots of load bias, and (b) load bias versus predicted $\mathrm{T}_{\max }$ values 


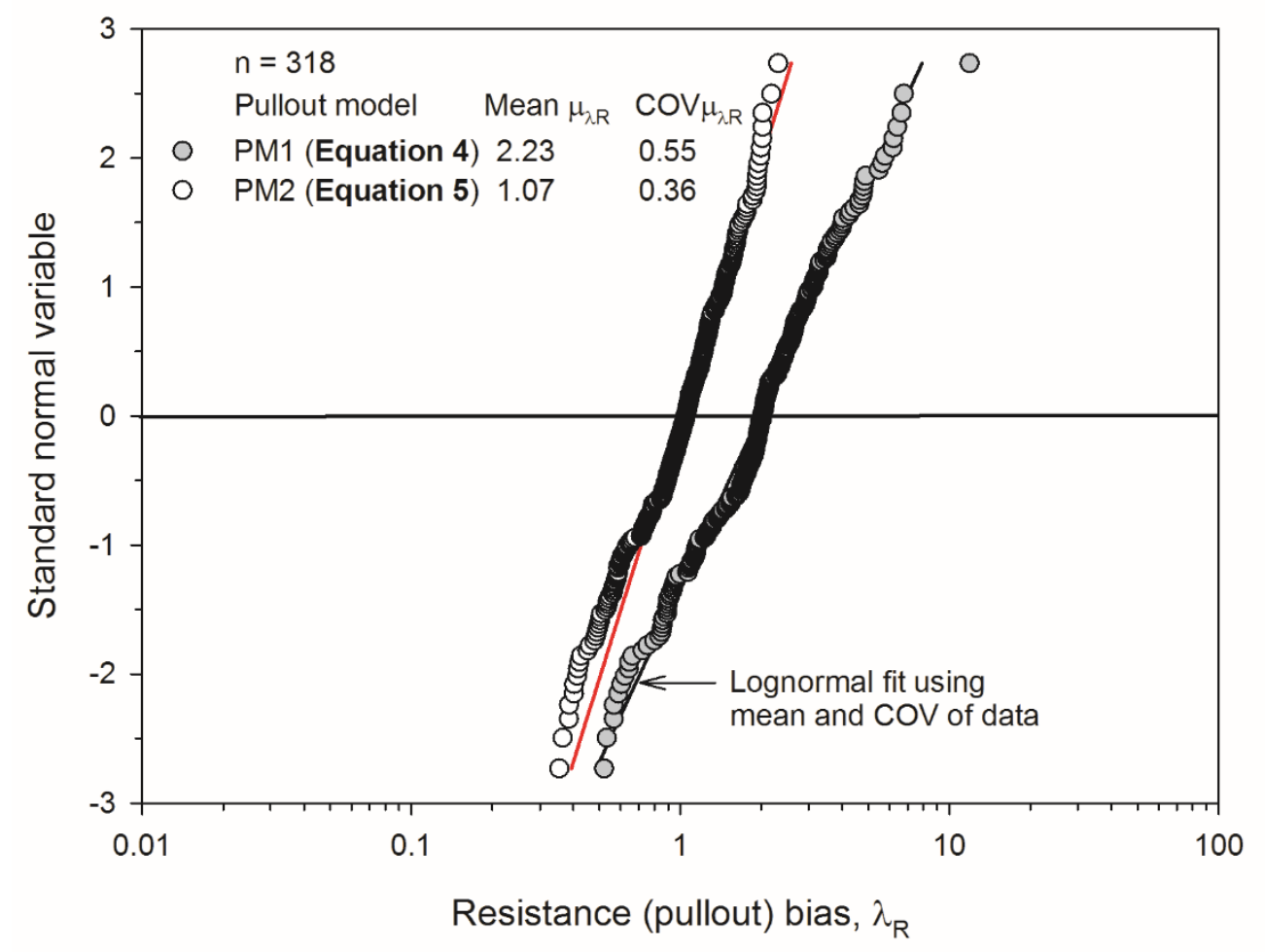

(a)

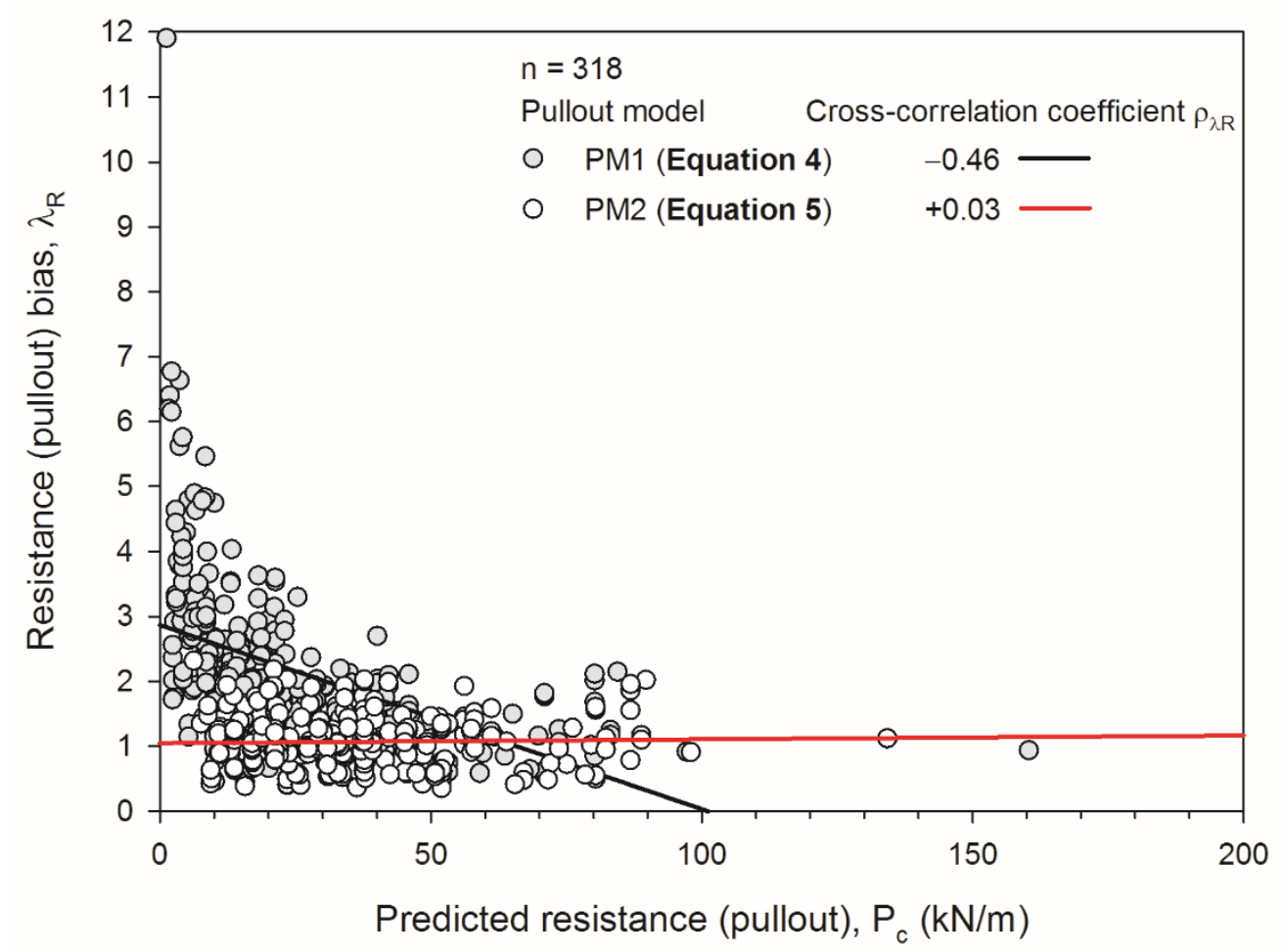

(b)

Figure 3. Resistance (pullout) bias data: (a) CDF plots of pullout bias, and (b) pullout bias versus predicted $P_{c}$ values 


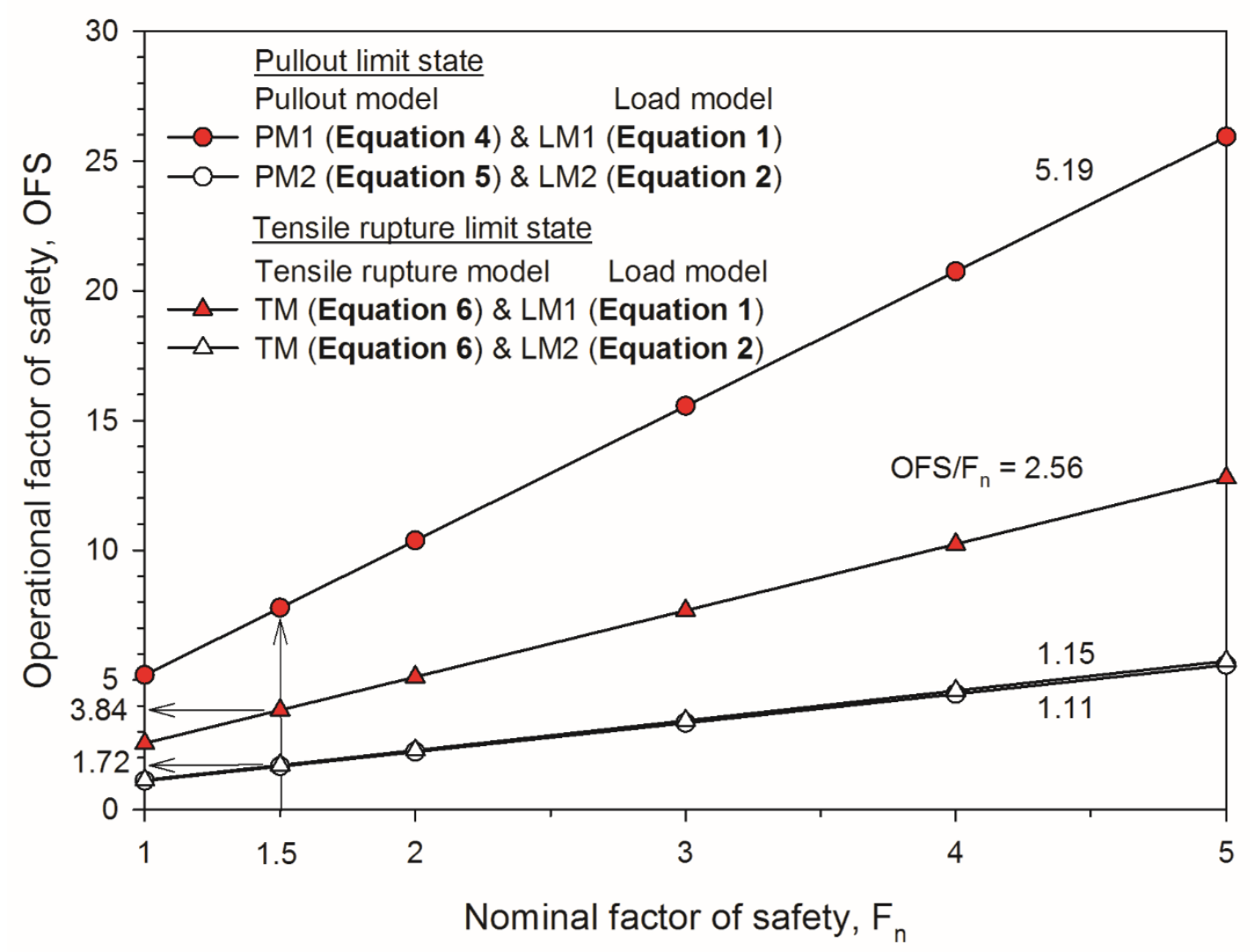

Figure 4. Operational factor of safety $\left(\mathrm{OFS}=\left(\frac{\mu_{\lambda R}}{\mu_{\lambda Q}}\right) \mathrm{F}_{\mathrm{n}}\right)$ versus factor of safety $\left(F_{n}=\frac{\mu_{\lambda R}}{\mu_{\lambda Q}}=\frac{R_{n}}{Q_{n}}\right)$ for pullout and tensile rupture limit states using different models 


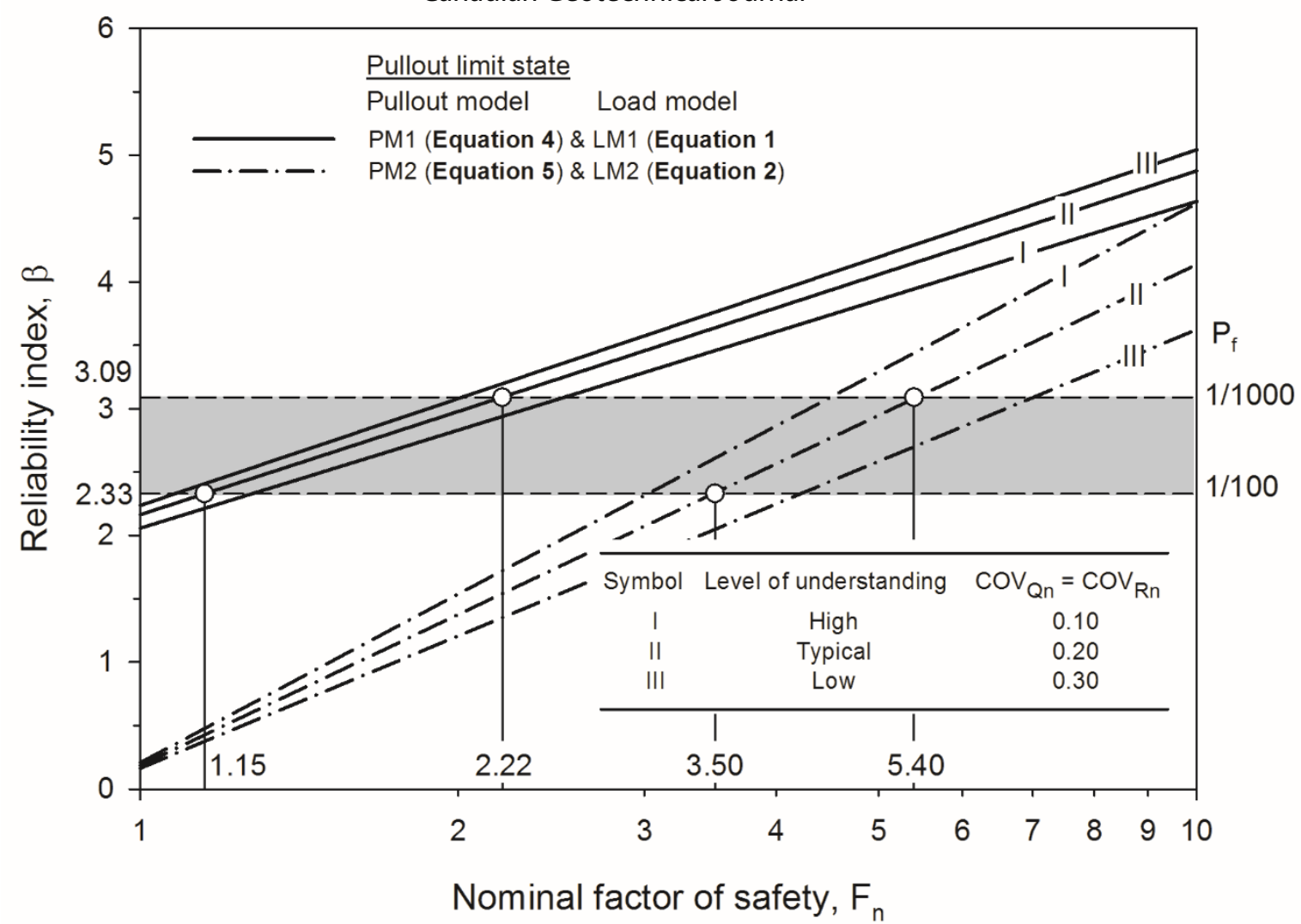

(a)

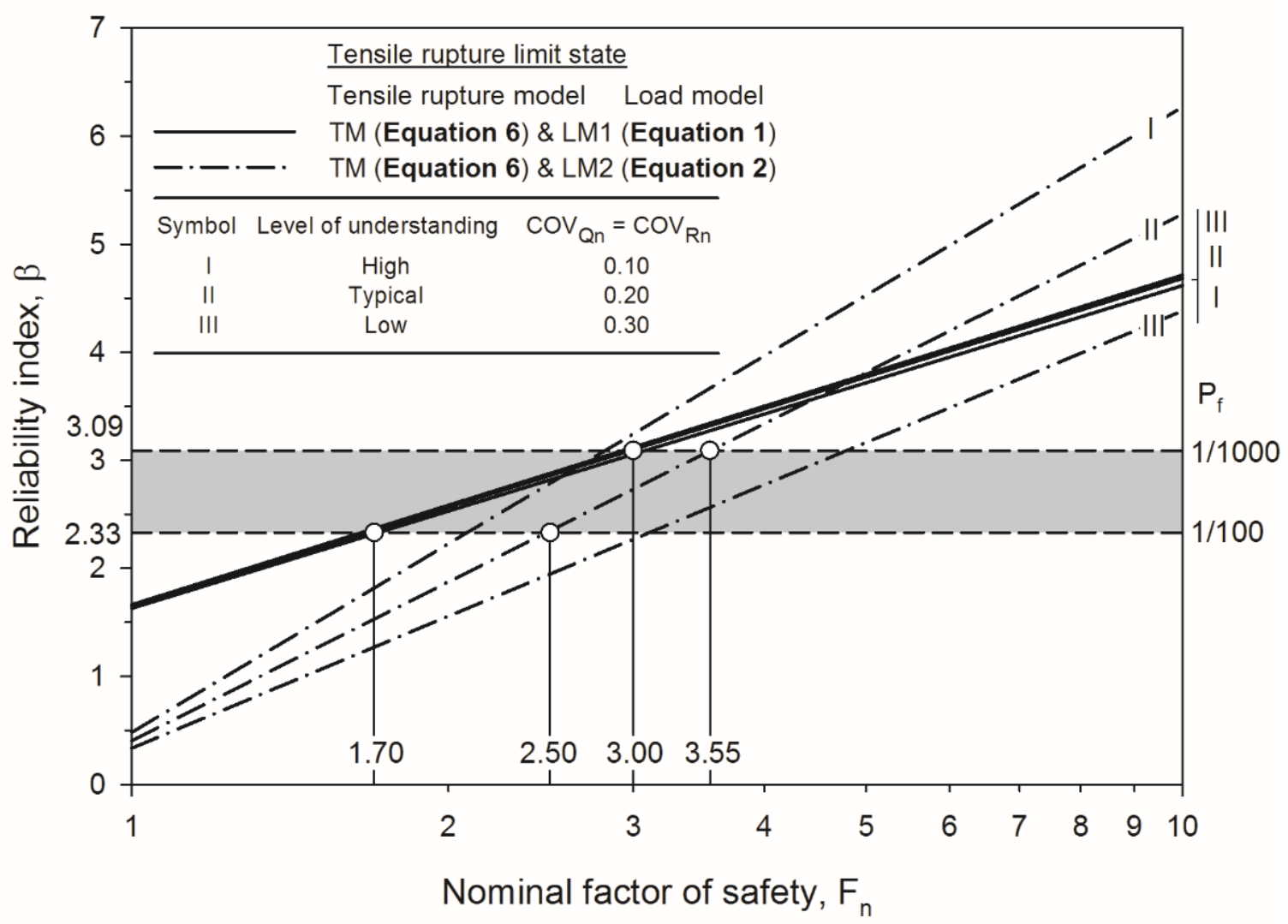

(b)

Figure 5. Reliability index $(\beta)$ versus factor of safety $\left(F_{n}\right)$ for different load and resistance models and levels of understanding: (a) pullout limit state; and (b) tensile rupture limit state 


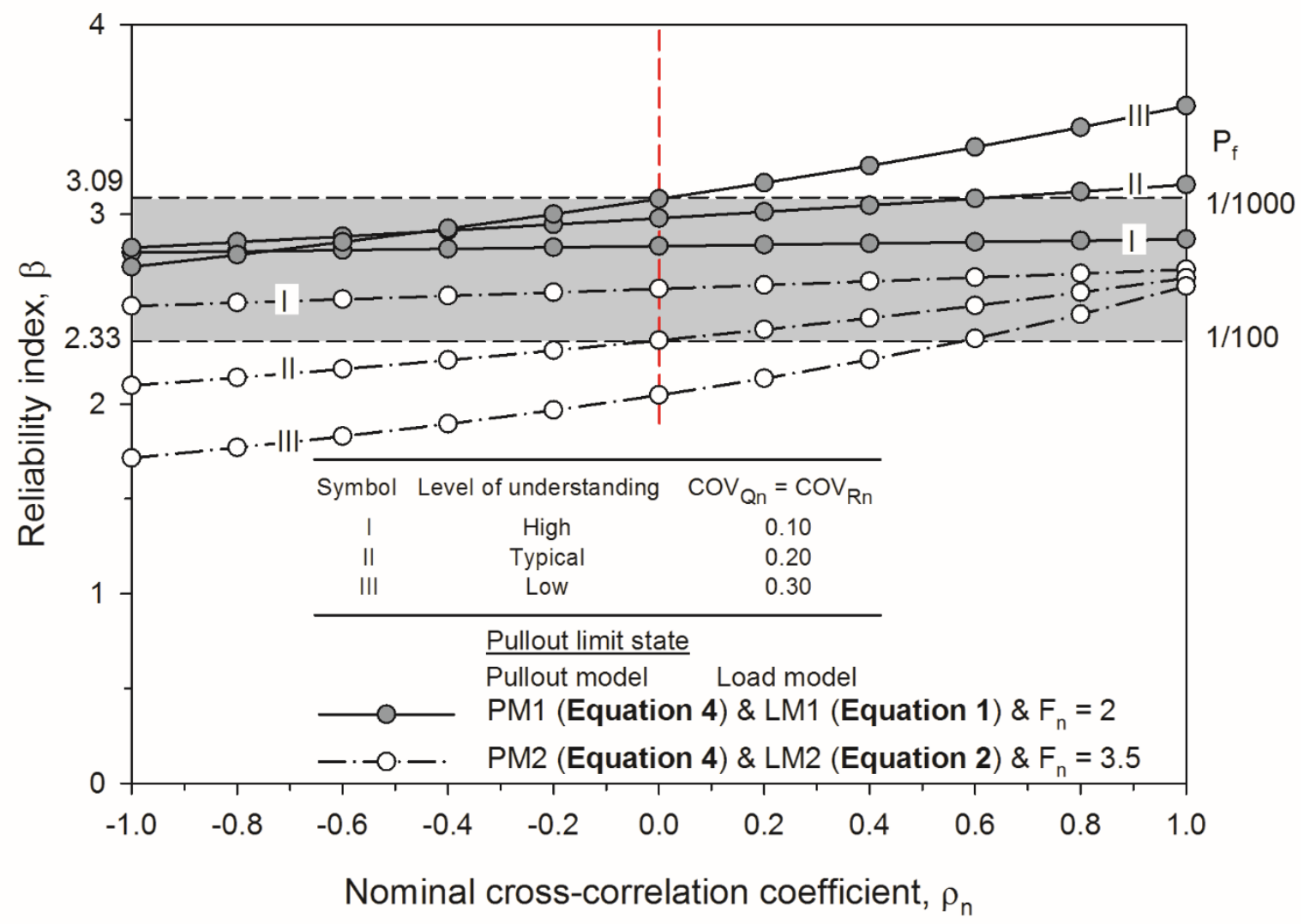

Figure 6. Reliability index $(\beta)$ versus nominal correlation coefficient $\left(\rho_{n}\right)$ for different load and resistance (pullout) models and levels of understanding 


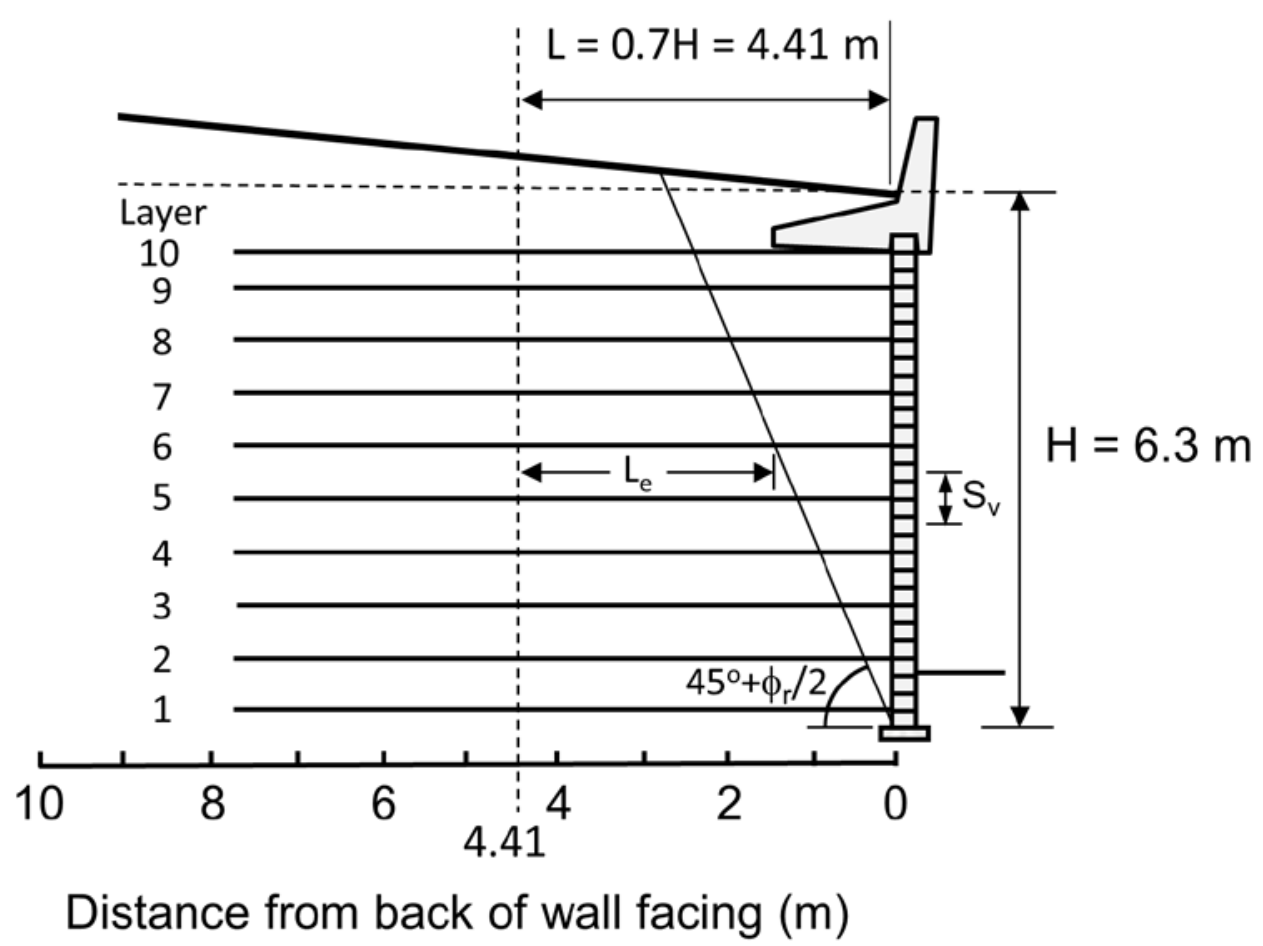

Figure 7. Wall GW26D used in design example (dimensions from Allen and Bathurst 2014b, 2018) 


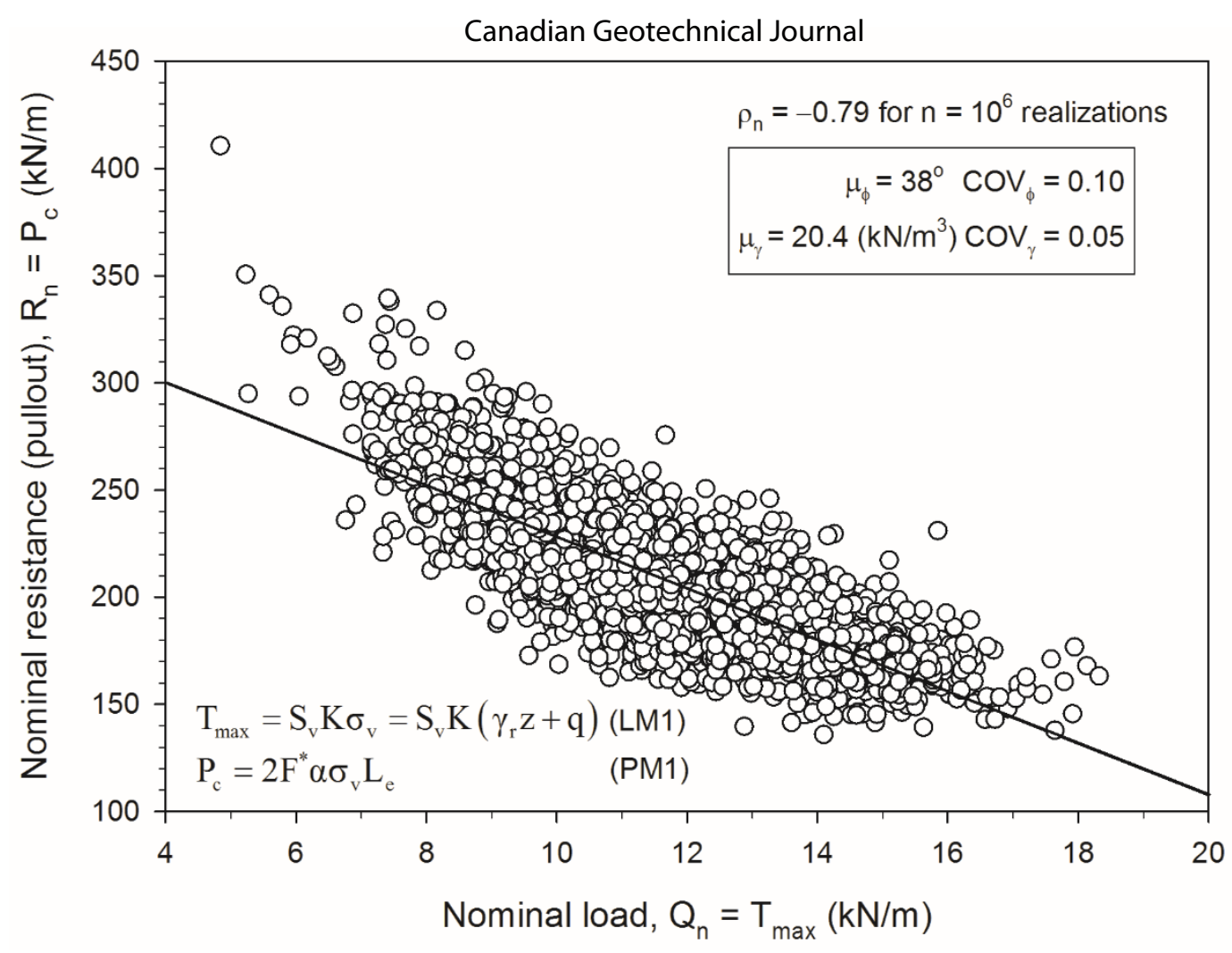

(a)

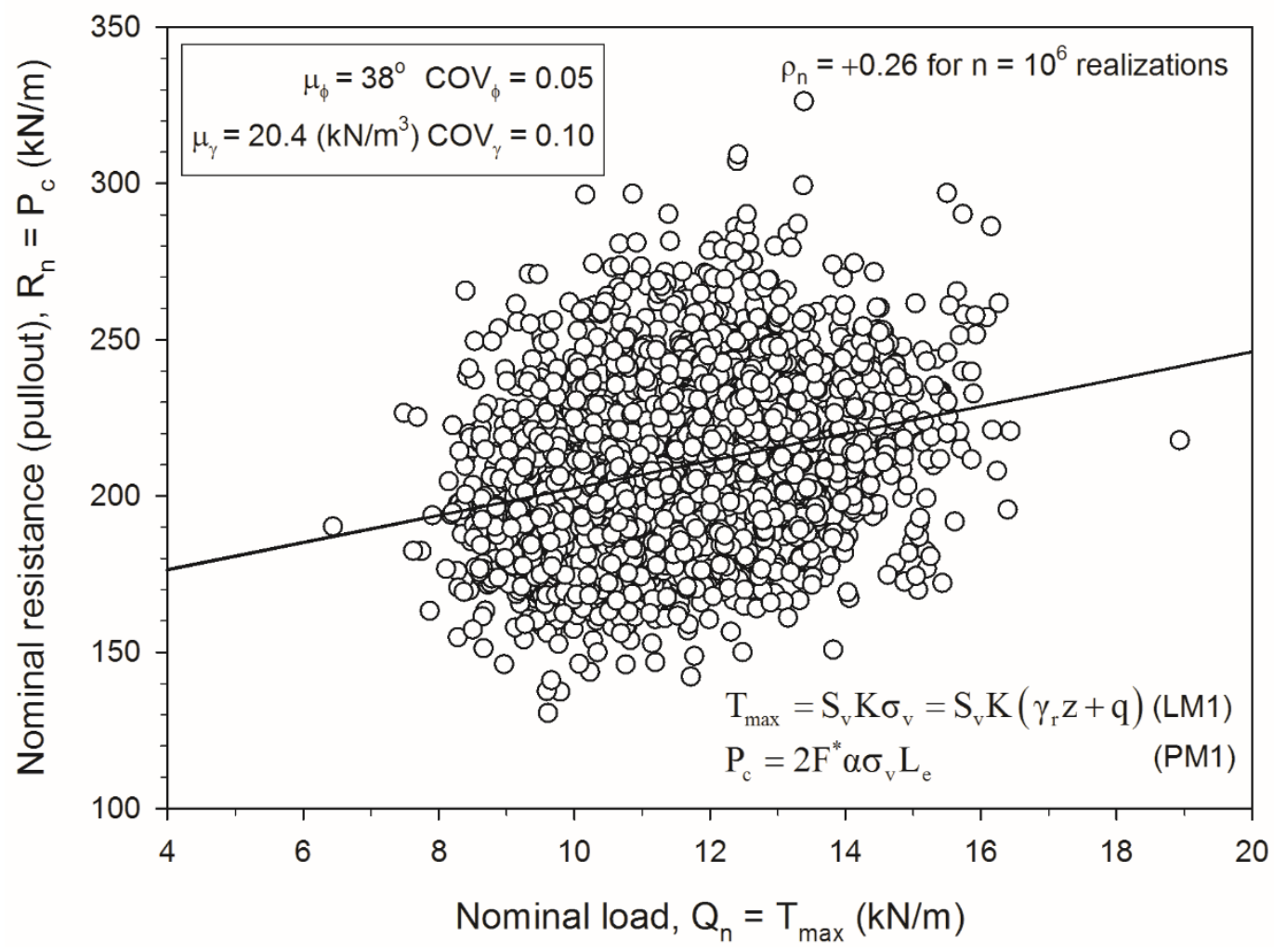

(b)

Figure 8. $\mathrm{R}_{\mathrm{n}}$ versus $\mathrm{Q}_{\mathrm{n}}$ for layer 5 using load model (LM1) and resistance model (PM1) with $\mu_{\phi}=38^{\circ}$ and $\mu_{\gamma}=20.4 \mathrm{kN} / \mathrm{m}^{3}$ : (a) $\mathrm{COV}_{\phi}=0.10, \mathrm{COV}_{\gamma}=0.05$ and; (b) $\mathrm{COV}_{\phi}=0.05, \mathrm{COV}_{\gamma}=$ 0.10 . Note: Only $n=3000$ data points shown for clarity; calculations for Layer 5 with $L_{e}=3.14$ 


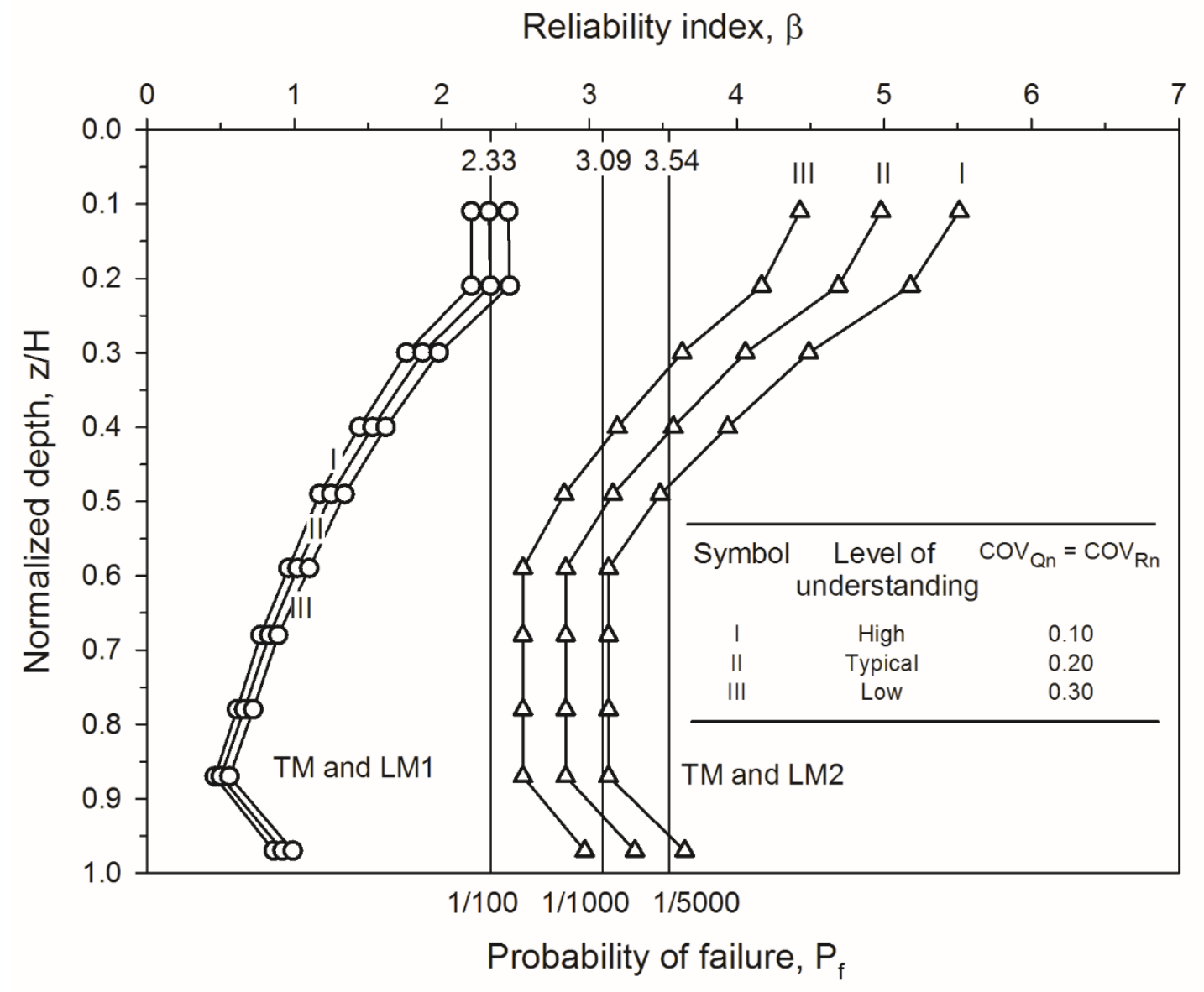

Figure 9. Reliability index for reinforcement layers in Wall GW26D using geogrid with $\mathrm{T}_{\text {ult }}$ $=24 \mathrm{kN} / \mathrm{m}$ and $\mathrm{J}=128 \mathrm{kN} / \mathrm{m}$ in design example (data from Table 7) 
Table 1. Summary of bias statistics and bias dependency values for load and resistance models for geogrid reinforced soil walls constructed with granular soil

\begin{tabular}{|c|c|c|c|c|c|c|}
\hline Model & Model equation & Number of data points, $n$ & Mean of bias & COV of bias & Bias dependency & Data source \\
\hline $\begin{array}{c}\text { Load model } \\
\text { LM1 } \\
\text { (FHWA 2009; } \\
\text { AASHTO 2017) }\end{array}$ & Equation 1 & 96 & $\mu_{\lambda Q}=0.43$ & $\mathrm{COV}_{\lambda \mathrm{Q}}=0.95$ & $\rho_{\mathrm{Q}}=-0.41$ & $\begin{array}{c}\text { Allen and } \\
\text { Bathurst (2015) }\end{array}$ \\
\hline $\begin{array}{c}\text { Load model } \\
\text { LM2 } \\
\text { (Allen and } \\
\text { Bathurst 2015) }\end{array}$ & Equation 2 & 96 & $\mu_{\lambda Q}=0.96$ & $\mathrm{COV}_{\lambda \mathrm{Q}}=0.36$ & $\rho_{Q}=0.09$ & $\begin{array}{c}\text { Allen and } \\
\text { Bathurst (2015) }\end{array}$ \\
\hline $\begin{array}{c}\text { Pullout model } \\
\text { PM1 } \\
\text { (FHWA 2009; } \\
\text { AASHTO 2017) }\end{array}$ & Equation 3 & 318 & $\mu_{\lambda R}=2.23$ & $\mathrm{COV}_{\lambda \mathrm{R}}=0.55$ & $\rho_{\mathrm{R}}=-0.46$ & $\begin{array}{c}\text { Huang and } \\
\text { Bathurst (2009) }\end{array}$ \\
\hline $\begin{array}{c}\text { Pullout model } \\
\text { PM2 } \\
\text { (Huang and } \\
\text { Bathurst 2009) }\end{array}$ & Equation 4 & 318 & $\mu_{\lambda \mathrm{R}}=1.07$ & $\mathrm{COV}_{\lambda \mathrm{R}}=0.36$ & $\rho_{\mathrm{R}}=0.03$ & $\begin{array}{c}\text { Huang and } \\
\text { Bathurst (2009) }\end{array}$ \\
\hline $\begin{array}{c}\text { Tensile rupture } \\
\text { TM } \\
\text { (AASHTO 2017) }\end{array}$ & Equation 5 & N/A & $\mu_{\lambda R}=1.10$ & $\mathrm{COV}_{\lambda \mathrm{R}}=0.10$ & $\rho_{\mathrm{R}}=0$ & $\begin{array}{c}\text { Bathurst et al. } \\
\qquad(2011)\end{array}$ \\
\hline
\end{tabular}

2 Note: $\mathrm{N} / \mathrm{A}=$ Not applicable

3 
7 Table 2. Input parameters for the design example using Wall GW26D from Allen and Bathurst (2014b, 2018)

8

\begin{tabular}{ll}
\hline Parameter & Value \\
\hline Soil friction angle, $\phi_{\mathrm{r}}\left(^{\circ}\right)$ & 38 \\
Moist soil unit weight, $\gamma_{\mathrm{r}}\left(\mathrm{kN} / \mathrm{m}^{3}\right)$ & 20.4 \\
Soil cohesion $(\mathrm{kPa})$ & 0 \\
Height of the wall, $\mathrm{H}(\mathrm{m})$ & 6.3 \\
Equivalent uniform height of surcharge, $\mathrm{S}(\mathrm{m})$ & 0.21 \\
Face batter angle, $\omega\left(^{\circ}\right)$ & 0 (Vertical) \\
Coefficient of active earth pressure, $\mathrm{K}_{\mathrm{avh}}=\mathrm{K}_{\mathrm{a}}$ & 0.238 \\
Number of reinforcement layers, $\mathrm{n}$ & 10 \\
Reference wall height, $\mathrm{H}_{\mathrm{ref}}(\mathrm{m})$ & 6 \\
Vertical spacing, $\mathrm{h}_{\mathrm{eff}}(\mathrm{m})$ & 0.6 \\
Thickness of the facing column, $\mathrm{b}(\mathrm{m})$ & 0.305 \\
Tributary vertical spacing of reinforcement layers, $\mathrm{S}_{\mathrm{v}}(\mathrm{m})$ & 1 for the top layer; \\
Allowable tensile load $(\mathrm{strength})$ at end of design life, $\mathrm{T}_{\mathrm{al}}(\mathrm{kN} / \mathrm{m})$ & 0.4 for the bottom layer; and \\
Reinforcement stiffness, $\mathrm{J}(\mathrm{kN} / \mathrm{m})$ & 0.6 for other layers \\
\hline
\end{tabular}


12 Table 3. Input parameters for Simplified Stiffness Method (Equation 3) (from Allen and Bathurst 2018)

\begin{tabular}{cccccccccccc}
\hline Layer & $\mathrm{z}(\mathrm{m})$ & $\mathrm{S}_{\mathrm{v}}(\mathrm{m})$ & $\mathrm{S}_{\text {global }}(\mathrm{kPa})$ & $\mathrm{S}_{\text {local }}(\mathrm{kPa})$ & $\mathrm{D}_{\text {tmax }}$ & $\mathrm{F}_{\mathrm{f}}$ & $\Phi_{\mathrm{g}}$ & $\Phi_{\text {local }}$ & $\Phi_{\mathrm{fb}}$ & $\Phi_{\mathrm{fs}}$ & $\Phi_{\mathrm{c}}$ \\
\hline 10 (top) & 0.70 & 1.00 & 556 & 350 & 0.29 & 1.87 & 0.25 & 0.77 & 1.0 & 0.81 & 1.0 \\
9 & 1.30 & 0.60 & 556 & 583 & 0.43 & 1.87 & 0.25 & 1.0 & 1.0 & 0.81 & 1.0 \\
8 & 1.90 & 0.60 & 556 & 583 & 0.58 & 1.87 & 0.25 & 1.0 & 1.0 & 0.81 & 1.0 \\
7 & 2.50 & 0.60 & 556 & 583 & 0.72 & 1.87 & 0.25 & 1.0 & 1.0 & 0.81 & 1.0 \\
6 & 3.10 & 0.60 & 556 & 583 & 0.87 & 1.87 & 0.25 & 1.0 & 1.0 & 0.81 & 1.0 \\
5 & 3.70 & 0.60 & 556 & 583 & 1.00 & 1.87 & 0.25 & 1.0 & 1.0 & 0.81 \\
4 & 4.30 & 0.60 & 556 & 583 & 1.00 & 1.87 & 0.25 & 1.0 & 1.0 & 0.81 \\
3 & 4.90 & 0.60 & 556 & 583 & 1.00 & 1.87 & 0.25 & 1.0 & 1.0 & 0.81 & 1.0 \\
2 & 5.50 & 0.60 & 556 & 583 & 1.00 & 1.87 & 0.25 & 1.0 & 1.0 & 0.81 & 1.0 \\
1 & 6.10 & 0.40 & 556 & 875 & 1.00 & 1.87 & 0.25 & 1.22 & 1.0 & 0.81 & 1.0 \\
\hline
\end{tabular}

13

14 Note: Reinforcement stiffness $\mathrm{J}=350 \mathrm{kN} / \mathrm{m}$ for all layers.

15

16 
17

18 Table 4. Summary of margins of safety for pullout limit state for Wall GW26D using pullout model PM1 AASHTO (2017) and load model LM1 AASHTO (2017)

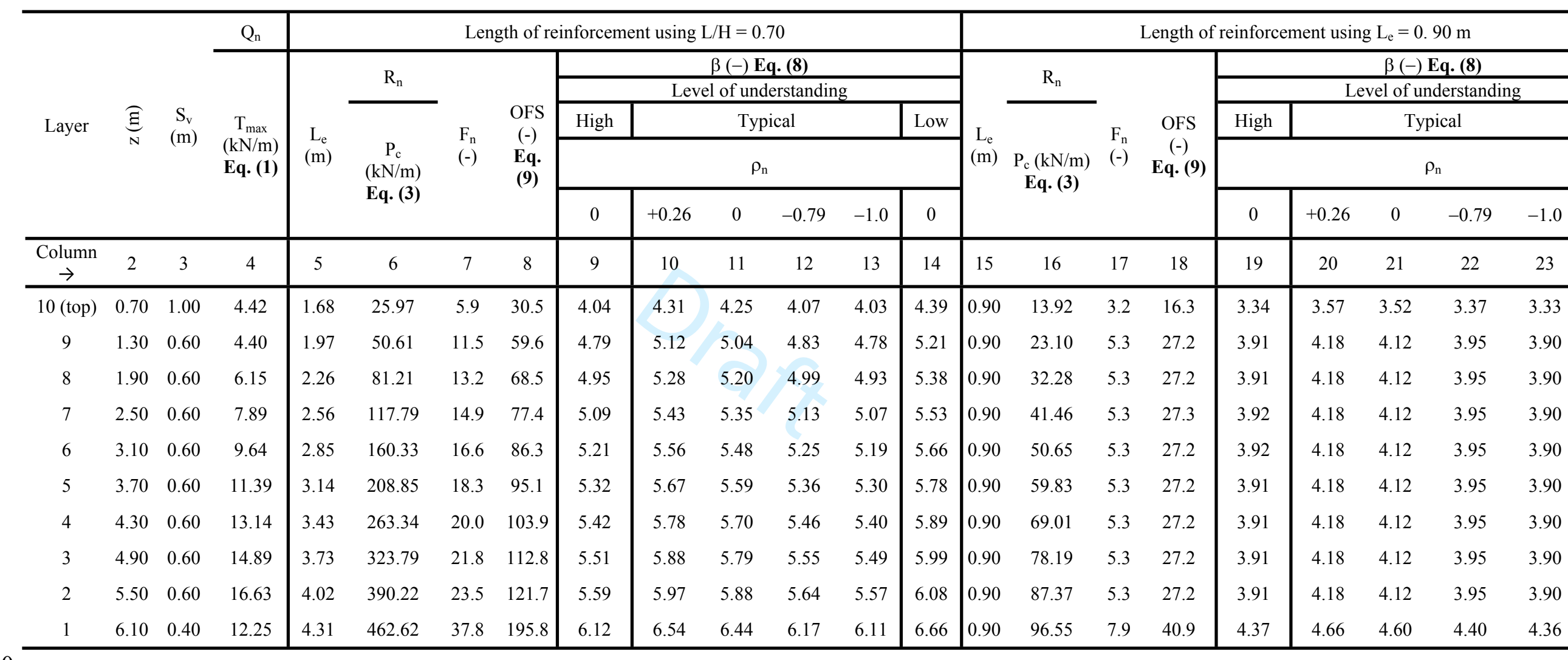

20 
21 Table 5. Summary of margins of safety for pullout limit state for Wall GW26D using pullout model PM2 (Huang and Bathurst 2009)

22 and load model LM2 (Allen and Bathurst 2015)

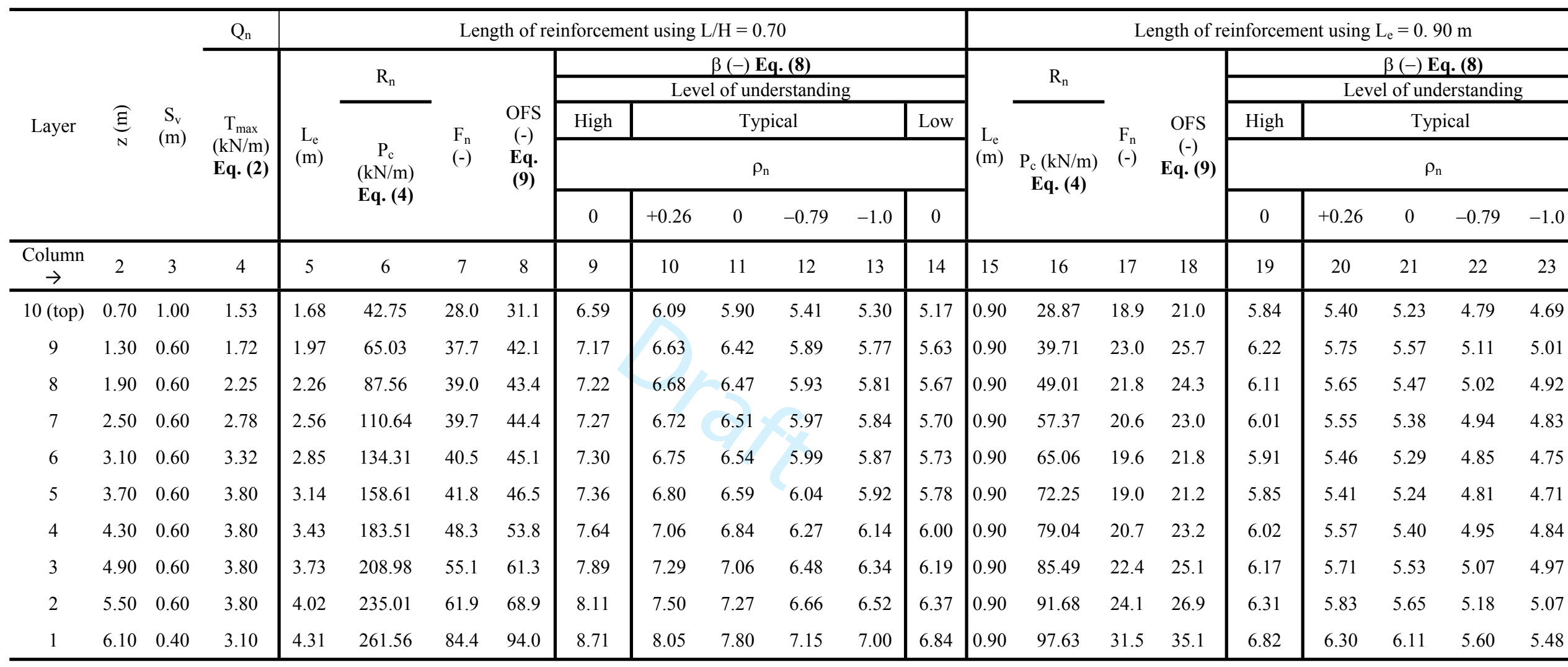


25 Table 6. Summary of margins of safety for rupture limit state for Wall GW26D using tensile rupture model TM (AASHTO 2017)

26 and load model LM1 (AASHTO 2017) and LM2 (Allen and Bathurst 2015): $\left(\mathrm{T}_{\mathrm{ult}}=54 \mathrm{kN} / \mathrm{m}\right.$ and J = 350 kN/m)

\begin{tabular}{|c|c|c|c|c|c|c|c|c|c|c|c|c|c|c|c|c|}
\hline \multirow{3}{*}{ Layer } & \multirow{3}{*}{$\begin{array}{c}\mathrm{z} \\
(\mathrm{m})\end{array}$} & \multirow{3}{*}{$\begin{array}{l}\mathrm{S}_{\mathrm{v}} \\
(\mathrm{m})\end{array}$} & \multicolumn{7}{|c|}{ LM1 and TM } & \multicolumn{7}{|c|}{ LM2 and TM } \\
\hline & & & \multirow{2}{*}{$\begin{array}{c}\mathrm{Q}_{\mathrm{n}} \\
\mathrm{T}_{\max } \\
(\mathrm{kN} / \mathrm{m}) \\
\text { Eq. (1) }\end{array}$} & \multirow{2}{*}{$\begin{array}{c}\mathrm{R}_{\mathrm{n}} \\
\mathrm{T}_{\mathrm{al}} \\
(\mathrm{kN} / \mathrm{m}) \\
\text { Eq. (5) }\end{array}$} & \multirow[b]{2}{*}{$F_{n}(-)$} & \multirow{2}{*}{$\begin{array}{l}\text { OFS (-) } \\
\text { Eq. (9) }\end{array}$} & \multicolumn{3}{|c|}{$\begin{array}{c}\beta(-) \text { Eq. }(\mathbf{8}) \\
\text { Level of understanding }\end{array}$} & \multirow{2}{*}{$\begin{array}{c}\mathrm{Q}_{\mathrm{n}} \\
\mathrm{T}_{\max } \\
(\mathrm{kN} / \mathrm{m}) \\
\text { Eq. (2) }\end{array}$} & $\mathrm{R}_{\mathrm{n}}$ & \multirow[b]{2}{*}{$F_{n}(-)$} & \multirow{2}{*}{$\begin{array}{c}\text { OFS } \\
(-) \\
\text { Eq. (9) }\end{array}$} & \multicolumn{3}{|c|}{$\begin{array}{c}\beta(-) \text { Eq. }(8) \\
\text { Level of understanding }\end{array}$} \\
\hline & & & & & & & High & Typical & Low & & $\begin{array}{c}\mathrm{T}_{\mathrm{al}} \\
(\mathrm{kN} / \mathrm{m}) \\
\text { Eq. (5) }\end{array}$ & & & High & Typical & Low \\
\hline 10 (top) & 0.70 & 1.00 & 4.42 & 15.1 & 3.4 & 8.7 & 3.26 & 3.44 & 3.61 & 1.53 & 15.1 & 9.9 & 11.3 & 6.46 & 5.83 & 5.18 \\
\hline 9 & 1.30 & 0.60 & 4.40 & 15.1 & 3.4 & 8.8 & 3.26 & 3.44 & 3.61 & 1.72 & 15.1 & 8.8 & 10.0 & 6.15 & 5.56 & 4.94 \\
\hline 8 & 1.90 & 0.60 & 6.15 & 15.1 & 2.5 & 6.3 & 2.82 & 2.98 & 3.13 & 2.25 & 15.1 & 6.7 & 7.7 & 5.45 & 4.93 & 4.39 \\
\hline 7 & 2.50 & 0.60 & 7.89 & 15.1 & 1.9 & 4.9 & 2.50 & 2.64 & 2.78 & 2.78 & 15.1 & 5.4 & 6.2 & 4.90 & 4.44 & 3.95 \\
\hline 6 & 3.10 & 0.60 & 9.64 & 15.1 & 1.6 & 4.0 & 2.24 & 2.37 & 2.49 & 3.32 & 15.1 & 4.5 & 5.2 & 4.44 & 4.02 & 3.59 \\
\hline 5 & 3.70 & 0.60 & 11.39 & 15.1 & 1.3 & 3.4 & 2.02 & 2.14 & 2.26 & 3.80 & 15.1 & 4.0 & 4.5 & 4.09 & 3.71 & 3.31 \\
\hline 4 & 4.30 & 0.60 & 13.14 & 15.1 & 1.1 & 2.9 & 1.83 & 1.94 & 2.05 & 3.80 & 15.1 & 4.0 & 4.5 & 4.09 & 3.71 & 3.31 \\
\hline 3 & 4.90 & 0.60 & 14.89 & 15.1 & 1.0 & 2.6 & 1.67 & 1.77 & 1.87 & 3.80 & 15.1 & 4.0 & 4.5 & 4.09 & 3.71 & 3.31 \\
\hline 2 & 5.50 & 0.60 & 16.63 & 15.1 & 0.91 & 2.3 & 1.52 & 1.62 & 1.71 & 3.80 & 15.1 & 4.0 & 4.5 & 4.09 & 3.71 & 3.31 \\
\hline 1 & 6.10 & 0.40 & 12.25 & 15.1 & 1.2 & 3.1 & 1.92 & 2.04 & 2.15 & 3.10 & 15.1 & 4.9 & 5.6 & 4.62 & 4.18 & 3.73 \\
\hline
\end{tabular}

27

28 Notes: Bold face values identify $\beta<2.33$ which is unacceptable for RBD. Italicized value identifies factor of safety $F_{n}<1$ which is

29 unacceptable for ASD.

30 
31 Table 7. Summary of margins of safety for rupture limit state for Wall GW26D using tensile rupture model TM (AASHTO 2017)

32 and load model LM1 (AASHTO 2017) and LM2 (Allen and Bathurst 2015): $\left(\mathrm{T}_{\mathrm{ult}}=24 \mathrm{kN} / \mathrm{m}\right.$ and J = $128 \mathrm{kN} / \mathrm{m}$ )

\begin{tabular}{|c|c|c|c|c|c|c|c|c|c|c|c|c|c|c|c|c|}
\hline \multirow{3}{*}{ Layer } & \multirow{3}{*}{$\begin{array}{c}\mathrm{z} \\
(\mathrm{m})\end{array}$} & \multirow{3}{*}{$\begin{array}{l}\mathrm{S}_{\mathrm{v}} \\
(\mathrm{m})\end{array}$} & \multicolumn{7}{|c|}{ LM1 and TM } & \multicolumn{7}{|c|}{ LM2 and TM } \\
\hline & & & \multirow{2}{*}{$\begin{array}{c}\mathrm{Q}_{\mathrm{n}} \\
\begin{array}{c}\mathrm{T}_{\max } \\
(\mathrm{kN} / \mathrm{m}) \\
\text { Eq. (1) }\end{array}\end{array}$} & \multirow{2}{*}{$\begin{array}{c}\mathrm{R}_{\mathrm{n}} \\
\begin{array}{c}\mathrm{T}_{\mathrm{al}} \\
(\mathrm{kN} / \mathrm{m}) \\
\text { Eq. (5) }\end{array}\end{array}$} & \multirow[b]{2}{*}{$F_{n}(-)$} & \multirow{2}{*}{$\begin{array}{l}\text { OFS (-) } \\
\text { Eq. (9) }\end{array}$} & \multicolumn{3}{|c|}{$\begin{array}{c}\beta(-) \text { Eq. (8) } \\
\text { Level of understanding }\end{array}$} & \multicolumn{2}{|l|}{$\mathrm{Q}_{\mathrm{n}}$} & \multirow[b]{2}{*}{$F_{n}(-)$} & \multirow{2}{*}{$\begin{array}{c}\text { OFS } \\
(-) \\
\text { Eq. (9) }\end{array}$} & \multicolumn{3}{|c|}{$\begin{array}{c}\beta(-) \text { Eq. (8) } \\
\text { Level of understanding }\end{array}$} \\
\hline & & & & & & & High & Typical & Low & $\begin{array}{c}T_{\max } \\
(\mathrm{kN} / \mathrm{m}) \\
\text { Eq. (2) }\end{array}$ & $\begin{array}{c}\mathrm{T}_{\mathrm{al}} \\
(\mathrm{kN} / \mathrm{m}) \\
\text { Eq. (5) }\end{array}$ & & & High & Typical & Low \\
\hline 10 (top) & 0.70 & 1.00 & 4.42 & 6.70 & 1.5 & 3.9 & 2.20 & 2.32 & 2.45 & 0.98 & 6.70 & 6.8 & 7.8 & 5.51 & 4.98 & 4.43 \\
\hline 9 & 1.30 & 0.60 & 4.40 & 6.70 & 1.5 & 3.9 & 2.20 & 2.33 & 2.46 & 1.11 & 6.70 & 6.0 & 6.9 & 5.18 & 4.69 & 4.17 \\
\hline 8 & 1.90 & 0.60 & 6.15 & 6.70 & 1.1 & 2.8 & 1.76 & 1.87 & 1.98 & 1.45 & 6.70 & 4.6 & 5.3 & 4.49 & 4.06 & 3.63 \\
\hline 7 & 2.50 & 0.60 & 7.89 & 6.70 & 0.8 & 2.2 & 1.44 & 1.53 & 1.62 & 1.79 & 6.70 & 3.7 & 4.3 & 3.94 & 3.57 & 3.19 \\
\hline 6 & 3.10 & 0.60 & 9.64 & 6.70 & 0.7 & 1.8 & 1.17 & 1.25 & 1.34 & 2.14 & 6.70 & 3.1 & 3.6 & 3.48 & 3.16 & 2.83 \\
\hline 5 & 3.70 & 0.60 & 11.39 & 6.70 & 0.6 & 1.5 & 0.96 & 1.02 & 1.10 & 2.45 & 6.70 & 2.7 & 3.1 & 3.13 & 2.84 & 2.55 \\
\hline 4 & 4.30 & 0.60 & 13.14 & 6.70 & 0.5 & 1.3 & 0.77 & 0.83 & 0.89 & 2.45 & 6.70 & 2.7 & 3.1 & 3.13 & 2.84 & 2.55 \\
\hline 3 & 4.90 & 0.60 & 14.89 & 6.70 & 0.5 & 1.2 & 0.61 & 0.66 & 0.72 & 2.45 & 6.70 & 2.7 & 3.1 & 3.13 & 2.84 & 2.55 \\
\hline 2 & 5.50 & 0.60 & 16.63 & 6.70 & 0.4 & 1.0 & 0.46 & 0.50 & 0.56 & 2.45 & 6.70 & 2.7 & 3.1 & 3.13 & 2.84 & 2.55 \\
\hline 1 & 6.10 & 0.40 & 12.25 & 6.70 & 0.5 & 1.4 & 0.86 & 0.92 & 0.99 & 2.00 & 6.70 & 3.4 & 3.8 & 3.65 & 3.31 & 2.97 \\
\hline
\end{tabular}

33

34 Notes: Bold face values identify $\beta<2.33$ which is unacceptable for RBD. Italicized values identify factors of safety $F_{n}<1$ which are

35 unacceptable for ASD. 